\title{
Model operator approach to the Lamb shift calculations in relativistic many-electron atoms
}

\author{
V. M. Shabaev and I. I. Tupitsyn \\ Department of Physics, St.Petersburg State University, \\ Ulianovskaya 1, Petrodvorets, St.Petersburg 198504, Russia \\ V. A. Yerokhin \\ St. Petersburg State Polytechnical University, Polytekhnicheskaya 29, St. Petersburg 195251, Russia
}

\begin{abstract}
A model operator approach to calculations of the QED corrections to energy levels in relativistic manyelectron atomic systems is developed. The model Lamb shift operator is represented by a sum of local and nonlocal potentials which are defined using the results of $a b$ initio calculations of the diagonal and nondiagonal matrix elements of the one-loop QED operator with H-like wave functions. The model operator can be easily included in any calculations based on the Dirac-Coulomb-Breit Hamiltonian. Efficiency of the method is demonstrated by comparison of the model QED operator results for the Lamb shifts in many-electron atoms and ions with exact QED calculations.
\end{abstract}

PACS numbers: 31.30.J-, 12.20.Ds

\section{INTRODUCTION}

A good starting point for the relativistic atomic calculations is given by the Dirac-Coulomb-Breit (DCB) equation. This equation can be solved with a high accuracy by using either the configuration-interaction Dirac-Fock (CI-DF) methods [1-7] or the relativistic many-body perturbation theory (RMBPT) methods [8-14]. In many cases the precision of these calculations has reached a level that requires evaluations of quantum electrodynamics (QED) effects. To date, the rigorous calculations of the QED effects in middle- and high- $Z$ systems are fully restricted to the $1 / Z$ perturbation theory (see, e.g., [15-19] and references therein). The perturbation theory methods have been also extended to many-electron ions and atoms employing an effective screening potential instead of the Coulomb one [20-27]. However, these methods are too complicated to be directly included into the DCB calculations. For this reason, numerous attempts have been undertaken to propose simple methods for incorporating the QED corrections into the CI-DF and RMBPT codes. These methods (see, e.g., [4, 28 -35] and references therein) are generally based on scaling the Lamb shift results for the Coulomb potential to other atomic potentials which include partially the screening effects. Such a scaling can be done either directly by using the Welton's idea [36] to express the main part of the self energy contribution in terms of $\vec{\nabla}^{2} V$ [4, 29, 34] or by introducing an effective short-range potential which fits the Lamb shifts for hydrogenlike ions [28, 30-33, 35].

In Ref. [37] it was shown that the QED corrections can be systematically included into an effective Hamiltonian acting in the space of the Slater determinants made up of oneelectron positive-energy states whose total (many-electron) energies are smaller than the pair-creation threshold. To the lowest order, this approach leads to a QED operator that, in principle, can be added to DCB Hamiltonian. The main goal of this paper is to represent this QED operator in a form that can be easily included in any calculations based on the DCB equation.
In the next section, we summarize the basic equations for the effective Hamiltonian that includes the one-loop QED corrections. Then we approximate the QED operator by a sum of short-range local and nonlocal potentials and calculate the model QED operator in a wide range of $Z=10-120$. Finally, the model QED operator is applied to calculations of the Lamb shifts in many-electron atoms and ions, and the results obtained are compared with other QED calculations.

Relativistic units $(\hbar=c=1)$ are used in the paper.

\section{EFFECTIVE HAMILTONIAN IN THE FRAMEWORK OF QED}

The systematic method to derive a Schrödinger-like equation for a relativistic many-electron atom from QED can be formulated within the two-time Green function (TTGF) method [38]. To determine such an equation, first of all one needs to choose the active space in which the effective Hamiltonian acts. Since rigorous calculations of the QED effects in middle- and high- $Z$ systems employ the perturbation theory starting from the Dirac equation with a local potential, the active space is generally considered to be formed either by a single or by (quasi)degenerate unperturbed states. These states are given by the Slater determinants made up of the solutions of the Dirac equation with the local potential considered. However, in Ref. [37] it was shown that the active space can be extended to all unperturbed states made up of one-electron positive-energy states whose total (many-electron) energies are smaller than the pair-creation threshold. Moreover, if the consideration is restricted to the lowest-order QED terms, the active space can be extended beyond the pair-creation threshold. For simplicity, this extention, having no effect on the accuracy of the calculations, is considered in the present paper. Using the derivations presented in Ref. [37], we summarize below the basic equations that are obtained with this choice of the active space.

To simplify the equations, we assume that the active space 


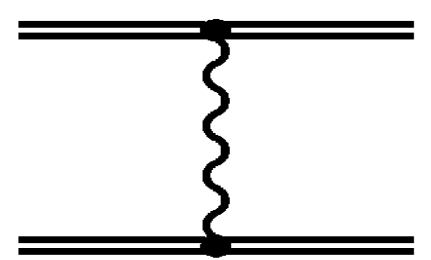

FIG. 1: One-photon exchange diagram.

is formed by the Slater determinants made up of the positiveenergy solutions of the Dirac equation with the Coulomb potential $V_{\mathrm{C}}(r)=-\alpha Z_{\text {nuc }}(r) / r$ (the effective charge $Z_{\text {nuc }}(r)$ accounts for the nuclear charge distribution):

$$
h^{\mathrm{D}} \psi_{n}=\varepsilon_{n} \psi_{n},
$$

where

$$
h^{\mathrm{D}}=\vec{\alpha} \cdot \vec{p}+m \beta+V_{\mathrm{C}}(r)
$$

is the one-electron Dirac Hamiltonian. We note, however, that all the equations can be easily adopted to the theory with the active space formed by the solutions in an effective potential $V_{\text {eff }}(r)$ (e.g., the Dirac-Hartree, the Kohn-Sham or a local version of the Dirac-Fock potential) that includes partly the screening effect. In this case, the interaction with the related counterterm $\left(V_{\mathrm{C}}(r)-V_{\mathrm{eff}}(r)\right)$ must be included in the total Hamiltonian. To construct the desired Hamiltonian, one should first consider the contribution from the one-photon exchange Feynman diagram (Fig. 1). Evaluation of this diagram with the TTGF method leads to the following symmetric form of the electron-electron interaction operator (for details see Refs. [37, 38]):

$$
\begin{aligned}
h^{\mathrm{int}}= & \sum_{\substack{k \neq l, m \neq n \\
+}}^{\left(\varepsilon_{k}, \varepsilon_{l}, \varepsilon_{m}, \varepsilon_{n}>0\right)}\left|\psi_{k} \psi_{l}\right\rangle\left\langle\psi_{k} \psi_{l}\right| \frac{1}{2}\left[I\left(\varepsilon_{k}-\varepsilon_{m}\right)\right. \\
& \left.+I\left(\varepsilon_{l}-\varepsilon_{n}\right)\right]\left|\psi_{m} \psi_{n}\right\rangle\left\langle\psi_{m} \psi_{n}\right|,
\end{aligned}
$$

where the indeces $k, l, m, n$ enumerate the positive-energy one-electron Dirac states, $\left|\psi_{k} \psi_{l}\right\rangle \equiv\left|\psi_{k}\right\rangle\left|\psi_{l}\right\rangle$ is the direct product of the one-electron Dirac wave functions $\psi_{k}\left(\overrightarrow{r_{1}}\right)$ and $\psi_{l}\left(\overrightarrow{r_{2}}\right)$,

$$
I(\omega)=e^{2} \alpha_{1}^{\rho} \alpha_{2}^{\sigma} D_{\rho \sigma}\left(\omega, r_{12}\right),
$$

$\alpha^{\rho} \equiv \gamma^{0} \gamma^{\rho}=(1, \boldsymbol{\alpha})$ are the Dirac matrices, $D_{\rho \sigma}\left(\omega, r_{12}\right)$ is the photon propagator, and $r_{12}=\left|\overrightarrow{r_{1}}-\overrightarrow{r_{2}}\right|$ is the interelectronic distance. It should be noted that the symmetric form of the frequency-dependent electron-electron interaction was

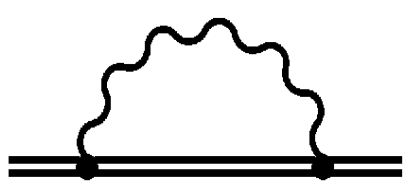

FIG. 2: Self-energy diagram.

first considered in Ref. [39]. The operator (3) defines the interaction between two electrons only. To get the total electronelectron interaction operator for a many-electron atom, one has to sum Eq. (3) over all pairs of atomic electrons:

$$
H^{\mathrm{int}}=\sum_{i<j} h_{i j}^{\mathrm{int}},
$$

where $h_{i j}^{\text {int }}$ is the two-electron operator (3) taken for electrons $i$ and $j$.

Taking $D_{\rho \sigma}\left(\omega, r_{i j}\right)$ in the Coulomb gauge at zero energy transfer $(\omega=0)$ leads to the Dirac-Coulomb-Breit Hamiltonian [40]:

$$
H^{\mathrm{DCB}}=\Lambda^{(+)}\left[\sum_{i} h_{i}^{\mathrm{D}}+\sum_{i<j} V_{i j}\right] \Lambda^{(+)},
$$

where the indeces $i$ and $j$ enumerate the atomic electrons, $\Lambda^{(+)}$is the product of the one-electron projectors on the positive-energy states (which correspond to the potential $V_{\mathrm{C}}$ ), $h_{i}^{\mathrm{D}}$ is the one-electron Dirac Hamiltonian (2) taken for electron $i$,

$$
\begin{aligned}
V_{i j} & =e^{2} \alpha_{i}^{\rho} \alpha_{j}^{\sigma} D_{\rho \sigma}\left(0, r_{i j}\right)=V_{i j}^{\mathrm{C}}+V_{i j}^{\mathrm{B}} \\
& =\frac{\alpha}{r_{i j}}-\alpha\left[\frac{\vec{\alpha}_{i} \cdot \vec{\alpha}_{j}}{r_{i j}}+\frac{1}{2}\left(\vec{\nabla}_{i} \cdot \vec{\alpha}_{i}\right)\left(\vec{\nabla}_{j} \cdot \vec{\alpha}_{j}\right) r_{i j}\right]
\end{aligned}
$$

is the the sum of the Coulomb and Breit electron-electron interaction operators, and $\alpha$ is the fine structure constant. It is well known that the DCB Hamiltonian accounts for the nonrelativistic and lowest-order relativistic contributions. In the Feynman gauge, to get the Hamiltonian to the same accuracy, one has to account for the higher-order photon exchange diagrams (see Ref. [37] and references therein).

As the next step, one should consider the contributions from the one-loop self-energy (SE) and vacuum-polarization (VP) diagrams presented in Figs. 2 and 3, respectively. The direct calculation of these contributions within the TTGF method leads to the following symmetric form of the one-electron QED operator $h^{\mathrm{QED}}$ [37]:

$$
\begin{aligned}
h^{\mathrm{QED}}= & h^{\mathrm{SE}}+h^{\mathrm{VP}}=\sum_{k, l}^{\left(\varepsilon_{k}, \varepsilon_{l}>0\right)}\left|\psi_{k}\right\rangle\left\langle\psi_{k}\right| \\
& \times\left[\frac{1}{2}\left(\Sigma^{\mathrm{SE}}\left(\varepsilon_{k}\right)+\Sigma^{\mathrm{SE}}\left(\varepsilon_{l}\right)\right)+V^{\mathrm{VP}}\right]\left|\psi_{l}\right\rangle\left\langle\psi_{l}\right|,
\end{aligned}
$$




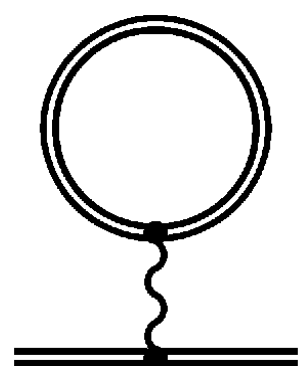

FIG. 3: Vacuum-polarization diagram.

where $\Sigma^{\mathrm{SE}}\left(\varepsilon_{k}\right)$ and $V^{\mathrm{VP}}$ are the renormalized SE and VP operators, respectively, and the sums over $k$ and $l$ go over all the positive-energy one-electron Dirac states. To get the total QED operator for a many-electron atom, one has to sum Eq. (8) over all atomic electrons:

$$
\begin{aligned}
H^{\mathrm{QED}} & =H^{\mathrm{SE}}+H^{\mathrm{VP}} \\
& =\sum_{i} h_{i}^{\mathrm{QED}}=\sum_{i}\left(h_{i}^{\mathrm{SE}}+h_{i}^{\mathrm{VP}}\right),
\end{aligned}
$$

where $h_{i}^{\mathrm{QED}}, h_{i}^{\mathrm{SE}}$, and $h_{i}^{\mathrm{VP}}$ are the one-electron operators (8) taken for electron $i$.

Thus, within the lowest-order QED approximation the total effective Hamiltonian can be presented as

$$
H=\Lambda^{(+)}\left[\sum_{i}\left(h_{i}^{\mathrm{D}}+h_{i}^{\mathrm{QED}}\right)+\sum_{i<j} h_{i j}^{\mathrm{int}}\right] \Lambda^{(+)},
$$

where the sums go over all atomic electrons and $h_{i j}^{\text {int }}$, which is the two-electron operator (3) considered for electrons $i$ and $j$, must be taken in the Coulomb gauge (if it is taken in the Feynman gauge, an additional term must be added to keep the same accuracy level [37]). In Eq. (10), all the operators are defined for the Coulomb potential $V_{\mathrm{C}}$. To get the corresponding Hamiltonian in the active space formed by the solutions in an effective potential $V_{\text {eff }}$, one should do the evident replacements in all the operators, including the projector, and add the $\operatorname{term} \Lambda^{(+)} \sum_{i}\left(V_{\mathrm{C}}\left(r_{i}\right)-V_{\mathrm{eff}}\left(r_{i}\right)\right) \Lambda^{(+)}$.

\section{MODEL QED OPERATOR}

Since the one-electron VP operator is given by the sum of the local Uehling and Wichmann-Kroll potentials [41], $V^{\mathrm{VP}}=V_{\mathrm{Uehl}}+V_{\mathrm{WK}}$, it can be easily included into the DCB equations. As is known, the dominant part of the VP contri- bution is represented by the Uehling potential:

$$
\begin{aligned}
V_{\text {Uehl }}(r)= & -\alpha Z \frac{2 \alpha}{3 \pi} \int_{0}^{\infty} d r^{\prime} 4 \pi r^{\prime} \rho\left(r^{\prime}\right) \\
& \times \int_{1}^{\infty} d t\left(1+\frac{1}{2 t^{2}}\right) \frac{\sqrt{t^{2}-1}}{t^{2}} \\
& \times \frac{e^{\left(-2 m\left|r-r^{\prime}\right| t\right)}-e^{\left(-2 m\left(r+r^{\prime}\right) t\right)}}{4 m r t},
\end{aligned}
$$

where $Z \rho(r)$ is the density of the nuclear charge distribution $\left(\int \rho(r) d \mathbf{r}=1\right)$. The Uehling potential can easily be evaluated employing the approximate formulas from Ref. [42]. Including the screening effect into this potential causes no problem but hardly affects the result (see, e.g., Ref. [23]). Evaluation of the Wichmann-Kroll potential is a much more difficult problem [43-45]. However, to a good accuracy, it can be calculated with the help of the approximate formulas derived in Ref. [46]. Therefore, in what follows, we restrict our consideration to the SE contribution only.

In principle, the operator $H^{\mathrm{SE}}$ defined by Eqs. (8)-(9) can be added to the DCB Hamiltonian to account for the lowestorder SE corrections. In practice, however, due to absence of rather simple algorithms for evaluation of the SE contributions for arbitrary states, we have to restrict $h^{\mathrm{SE}}$ to its matrix elements between a finite number of low-lying one-electron Dirac-Coulomb (or other effective potential) wave functions. This restriction strongly enlarges the interaction range of the SE operator and excludes highly-excited bound and continuum spectrum components from the active space. As a result, such a potential may lead to the SE corrections which strongly deviate from the correct ones. For instance, in case of H-like ions it gives zero results for the states with the principal quantum number $n \geq 4$, provided the sums in (8) are limited by $n_{k}, n_{l} \leq 3$. To solve these problems, we modify the operator $h^{\mathrm{SE}}$ in two steps.

As the first step, to minimize the deviation of the representation (8), restricted to a finite number of states, from the exact one, we separate out a local (with respect to $r$ ) potential $V_{\mathrm{loc}}^{\mathrm{SE}}$ from the SE operator and employ formula (8) for the remaining SE part only. Such a separation can be justified by the fact that a dominant part of the nonrelativistic SE operator can be represented by a local short-range potential [36]. Due to the conservation of the angular quantum numbers by the one-electron SE operator, we can choose the local part to be different for different $\kappa=(-1)^{j+l+1 / 2}(j+1 / 2)$. With this in mind, we introduce the projector $P_{\kappa}$ which acts only on the angular variables and is defined by its kernel as

$$
\begin{aligned}
& P_{\kappa}\left(\mathbf{n}, \mathbf{n}^{\prime}\right)= \\
& \left(\begin{array}{cc}
\sum_{m} \Omega_{\kappa m}(\mathbf{n}) \Omega_{\kappa m}^{\dagger}\left(\mathbf{n}^{\prime}\right) & 0 \\
0 & \sum_{m} \Omega_{-\kappa m}(\mathbf{n}) \Omega_{-\kappa m}^{\dagger}\left(\mathbf{n}^{\prime}\right)
\end{array}\right),
\end{aligned}
$$


where $\Omega_{\kappa m}(\mathbf{n})$ is a spherical spinor. Then, the local potential is given by

$$
V_{\mathrm{loc}}^{\mathrm{SE}}=\sum_{\kappa} V_{\mathrm{loc}, \kappa}^{\mathrm{SE}} P_{\kappa},
$$

where $V_{\text {loc }, \kappa}^{\mathrm{SE}}(r)$ is a short-range radial potential which can be chosen differently for different values of $\kappa$. Strictly speaking, the potential $V_{\mathrm{loc}}^{\mathrm{SE}}$ is semilocal. However, here and in what follows we label it as "local", keeping in mind that it is local only at a given value of $\kappa$. We put

$$
V_{\mathrm{loc}, \kappa}^{\mathrm{SE}}(r)=A_{\kappa} \exp \left(-r / \lambda_{C}\right),
$$

where the constant $A_{\kappa}$ is chosen to reproduce the SE shift for the lowest energy level at the given $\kappa$ in the corresponding H-like ion, and $\lambda_{C}=\hbar /(m c)$.

As the second step, we restrict the active space of the remaining $\mathrm{SE}$ operator, $h^{\mathrm{SE}}-V_{\mathrm{loc}}^{\mathrm{SE}}$, to the basis functions $\left\{\phi_{i}(\mathbf{r})\right\}_{i=1}^{n}$ which, having the same angular parts as the oneelectron Dirac-Coulomb functions $\left\{\psi_{i}(\mathbf{r})\right\}_{i=1}^{n}$, are localized at smaller distances compared to the Dirac-Coulomb ones. The specific choice of the functions $\left\{\phi_{i}(\mathbf{r})\right\}_{i=1}^{n}$ will be given below. With these functions, we approximate the one-electron SE operator as follows

$$
h^{\mathrm{SE}}=V_{\mathrm{loc}}^{\mathrm{SE}}+\sum_{i, k=1}^{n}\left|\phi_{i}\right\rangle B_{i k}\left\langle\phi_{k}\right|,
$$

where the matrix $B_{i k}$ has to be determined in such a way that the matrix elements of the model SE operator with the $\mathrm{H}$ like wave functions, corresponding to the space under consideration, coincide with the exact ones. This leads to the equations

$$
\begin{aligned}
& \sum_{j, l=1}^{n}\left\langle\psi_{i} \mid \phi_{j}\right\rangle B_{j l}\left\langle\phi_{l} \mid \psi_{k}\right\rangle \\
&=\left\langle\psi_{i}\left|\left[\frac{1}{2}\left(\Sigma\left(\varepsilon_{i}\right)+\Sigma\left(\varepsilon_{k}\right)\right)-V_{\text {loc }}^{\mathrm{SE}}\right]\right| \psi_{k}\right\rangle
\end{aligned}
$$

Introducing the matrix $D_{i k}=\left\langle\phi_{i} \mid \psi_{k}\right\rangle$, we get

$$
\begin{aligned}
B_{i k}= & \sum_{j, l=1}^{n}\left(\left(D^{t}\right)^{-1}\right)_{i j}\left\langle\psi_{j}\right|\left[\frac{1}{2}\left(\Sigma\left(\varepsilon_{j}\right)+\Sigma\left(\varepsilon_{l}\right)\right)\right. \\
& \left.-V_{\mathrm{loc}}^{\mathrm{SE}}\right]\left|\psi_{l}\right\rangle\left(D^{-1}\right)_{l k} .
\end{aligned}
$$

Therefore, the model one-electron SE operator can be written as

$$
\begin{aligned}
h^{\mathrm{SE}}= & V_{\mathrm{loc}}^{\mathrm{SE}}+\sum_{i, k=1}^{n} \sum_{j, l=1}^{n}\left|\phi_{i}\right\rangle\left(\left(D^{t}\right)^{-1}\right)_{i j} \\
& \left.\times\left\langle\psi_{j}\left|\left[\frac{1}{2}\left(\Sigma\left(\varepsilon_{j}\right)+\Sigma\left(\varepsilon_{l}\right)\right)-V_{\mathrm{loc}}^{\mathrm{SE}}\right]\right| \psi_{l}\right\rangle\right] \\
& \times\left(D^{-1}\right)_{l k}\left\langle\phi_{k}\right| .
\end{aligned}
$$

Now let us consider the choice of the functions $\left\{\phi_{i}(\mathbf{r})\right\}_{i=1}^{n}$. From one side, since we use the SE matrix elements calculated with the hydrogenlike wave functions, these functions should be chosen rather close to the H-like ones. From the other side, because of a short interaction range of the SE operator, they should vanish at smaller distances compared to the $\mathrm{H}$-like wave functions. With this in mind, we construct them using the H-like wave functions multiplied with the factor

$$
\rho_{l}(r)=\exp \left(-2 \alpha Z\left(r / \lambda_{C}\right) /(1+l)\right)
$$

where $l=|\kappa+1 / 2|-1 / 2$ is the orbital angular momentum of the state under consideration. The simple choice $\phi_{i}(\mathbf{r})=\rho_{l_{i}}(r) \psi_{i}(\mathbf{r})$ fits the goal but, due to a rather similar behaviour of the wave functions for different values of the principal quantum number at small $r$, gives a matrix $D$ close to degenerate one and, therefore, leads to a rather singular matrix $D^{-1}$. For this reason, we consider a slightly different choice. In what follows, we restrict the basis functions by $n s, n p_{1 / 2}, n p_{3 / 2}, n d_{3 / 2}$, and $n d_{5 / 2}$ states with the principal quantum number $n \leq 3$ for the $s$ states and $n \leq 4$ for the $p$ and $d$ states, and put

$$
\phi_{i}(\mathbf{r})=\frac{1}{2}\left(I-(-1)^{s_{i}} \beta\right) \rho(r) \psi_{i}(\mathbf{r})
$$

where $I$ is the identity matrix, $\beta$ is the standard Dirac matrix, the index $s_{i}=n_{i}-l_{i}$ enumerates the positive energy states at the given $\kappa$, and $n_{i}$ is the principal quantum number. With this choice, one easily finds

$$
\begin{gathered}
D_{11}=\int_{0}^{\infty} d r r^{2} g_{1}^{2}(r) \rho_{l}(r), \quad D_{12}=\int_{0}^{\infty} d r r^{2} g_{1}(r) g_{2}(r) \rho_{l}(r), \\
D_{13}=D_{31}=\int_{0}^{\infty} d r r^{2} g_{1}(r) g_{3}(r) \rho_{l}(r), \quad D_{21}=\int_{0}^{\infty} d r r^{2} f_{1}(r) f_{2}(r) \rho_{l}(r), \\
D_{22}=\int_{0}^{\infty} d r r^{2} f_{2}^{2}(r) \rho_{l}(r), \quad D_{23}=\int_{0}^{\infty} d r r^{2} f_{2}(r) f_{3}(r) \rho_{l}(r), \\
D_{32}=\int_{0}^{\infty} d r r^{2} g_{2}(r) g_{3}(r) \rho_{l}(r), \quad D_{33}=\int_{0}^{\infty} d r r^{2} g_{3}^{2}(r) \rho_{l}(r),
\end{gathered}
$$


where $g_{i}(r)$ and $f_{i}(r)$ are the upper and lower radial components of the hydrogenlike wave functions and the index $i$ enumerates the positive-energy states at the given $\kappa$. The explicit formulas for the calculation of the inverse matrix can be found in the standard textbooks.

Thus, in what follows we use the model one-electron SE operator given by

$$
\begin{aligned}
h^{\mathrm{SE}}= & V_{\mathrm{loc}}^{\mathrm{SE}}+\frac{1}{4} \sum_{i, k} \sum_{j, l}\left(I-(-1)^{s_{i}} \beta\right) \rho_{l_{i}}(r)\left|\psi_{i}\right\rangle \\
& \times\left(\left(D^{t}\right)^{-1}\right)_{i j}\left\langle\psi_{j}\left|\left[\frac{1}{2}\left(\Sigma\left(\varepsilon_{j}\right)+\Sigma\left(\varepsilon_{l}\right)\right)-V_{\mathrm{loc}}^{\mathrm{SE}}\right]\right| \psi_{l}\right\rangle \\
& \times\left(D^{-1}\right)_{l k}\left\langle\psi_{k}\right| \rho_{l_{k}}(r)\left(I-(-1)^{s_{k}} \beta\right),
\end{aligned}
$$

where the summations run over $n s$ states with the principal quantum number $n \leq 3$ and over $n p_{1 / 2}, n p_{3 / 2} n d_{3 / 2}, n d_{5 / 2}$ states with $n \leq 4, \rho_{l_{i}}(r)=\exp \left(-2 \alpha Z\left(r / \lambda_{C}\right) /\left(1+l_{i}\right)\right)$,

$$
D_{i k}=\frac{1}{2}\left\langle\psi_{i}\left|\left(I-(-1)^{s_{i}} \beta\right) \rho_{l_{i}}(r)\right| \psi_{k}\right\rangle,
$$

and $V_{\mathrm{loc}}^{\mathrm{SE}}$ is defined by Eqs. (13)-(14) .

\section{MATRIX ELEMENTS OF THE EXACT SELF-ENERGY OPERATOR}

To complete our construction of the model SE operator, we need the diagonal and non-diagonal matrix elements of the exact SE operator $\Sigma(\varepsilon)$ with the hydrogenlike wave functions. Calculations of the SE corrections reported previously in the literature [47-49] were performed for the diagonal matrix elements only. In the present work, we extend these calculations to both the diagonal and non-diagonal matrix elements of the one-loop SE operator. Our calculation was carried out into two steps. First, we evaluated the SE matrix element for the point nucleus by using the numerical method described in detail in Refs. [50, 51]. Next, we separately calculated the finite nuclear size correction, as described in Ref. [52]. The finite nuclear size effect was calculated with the standard twoparameter Fermi model for the nuclear charge distribution.

The results of our calculations for the $n s, n p_{1 / 2}, n p_{3 / 2}$, $n d_{3 / 2}$, and $n d_{5 / 2}$ states with $n$ up to 5 are presented in Tables IIIIV, respectively. They are expressed in terms of the function $F_{i k}(\alpha Z)$ defined by

$$
\begin{aligned}
\Sigma_{i k} & \equiv\left\langle\psi_{i}\left|\frac{1}{2}\left(\Sigma\left(\varepsilon_{i}\right)+\Sigma\left(\varepsilon_{k}\right)\right)\right| \psi_{k}\right\rangle \\
& =\frac{\alpha}{\pi} \frac{(\alpha Z)^{4}}{\left(n_{i} n_{k}\right)^{3 / 2}} F_{i k}(\alpha Z) m c^{2},
\end{aligned}
$$

where $n_{i}$ and $n_{k}$ are the principal quantum numbers of the $i$ and $k$ states, respectively. In the tables, the results are presented separately for the point nucleus and for the extended nucleus (except for the cases when both results coincide). If no error is specified, the results are supposed to be accurate to all digits quoted. In the case of diagonal matrix elements, excellent agreement with previous results [47-49] is observed.
In this paper, to define the model SE operator we use the values $F_{i k}(\alpha Z)$ with the principal quantum numbers $n_{i}, n_{k} \leq 3$ for the $s$ states and $n_{i}, n_{k} \leq 4$ for the $p$ and $d$ states. As to the other data presented in the tables, they can be used for test calculations with $\mathrm{H}$-like ions (see the next section) as well as for extending the active space of the model SE operator.

To obtain the function $F_{i k}(\alpha Z)$ for values of $Z$ not listed in the tables, one may use a polynomial interpolation, applied to the function

$$
G_{i k}(\alpha Z)=F_{i k}(\alpha Z)-\delta_{l 0}(4 / 3) \ln (\alpha Z)^{-2} .
$$

Here, following to Ref. [53], we have subtracted the log term which represents the small- $\alpha Z$ behaviour of $F_{i k}(\alpha Z)$ for $s$ states $(l=0)$. The interpolation function is thus given by [53]

$$
\begin{aligned}
F_{i k}^{\prime}(\alpha Z)= & \delta_{l 0}(4 / 3) \ln (\alpha Z)^{-2}+\sum_{n=1}^{N}\left[\prod_{m \neq n} \frac{Z-Z_{m}}{Z_{n}-Z_{m}}\right] \\
& \times\left[F_{i k}\left(\alpha Z_{n}\right)-\delta_{l 0}(4 / 3) \ln \left(\alpha Z_{n}\right)^{-2}\right] .
\end{aligned}
$$

\section{CALCULATIONS WITH THE MODEL SELF-ENERGY OPERATOR}

Since the model SE operator is constructed using the SE matrix elements with $\mathrm{H}$-like wave functions of the $n s$ states at $n \leq 3$ and the $n p$ and $n d$ states at $n \leq 4$, first of all, we should consider how it works for $\mathrm{H}$-like states with higher values of $n$. In Table VI we present the SE shifts for the $4 s, 5 s$, $5 p_{1 / 2}, 5 p_{3 / 2}, 5 d_{3 / 2}$, and $5 d_{5 / 2}$ states in H-like ions, obtained using the model SE operator, $\left\langle v\left|h^{\mathrm{SE}}\right| v\right\rangle$, and compare them with the corresponding exact results. To demonstrate the importance of the nonlocal part of $h^{\mathrm{SE}}$, we present also the local $\left\langle v\left|V_{\mathrm{loc}}^{\mathrm{SE}}\right| v\right\rangle$ contribution. As one can see from the table, for the $s$ states the difference between the exact and model SE operator results does not exceed $1 \%$. As to the $p$ and $d$ states, despite the relative value of the difference is significantly bigger than for the $s$ states, its absolute value, expressed in terms of the functions $F(\alpha Z)$, does not exceed 0.01 . We stress also the importance of the nonlocal part of the model SE operator: for the $s$ states the difference between the local part and the total result can amount to about $30 \%$.

To demonstrate the efficiency of the method, we also applied it to calculations of the Lamb shifts in neutral alkali metals, $\mathrm{Cu}$-like ions, superheavy atoms, and Li-like ions.

Calculations of the Lamb shift in alkali metals were considered in Refs. [20, 54]. In Ref. [20], it was calculated in the potential $V_{\text {eff }}(r)$, which is defined in terms of an effective charge $Z_{\text {eff }}(r)$ through

$$
V_{\mathrm{eff}}(r)=-\frac{\alpha Z_{\mathrm{eff}}(r)}{r},
$$

where

$Z_{\text {eff }}(r)=Z_{\text {nuc }}(r)-r \int_{0}^{\infty} d r^{\prime} \frac{1}{r_{>}} \rho_{\mathrm{t}}\left(r^{\prime}\right)+x_{\alpha}\left[\frac{81}{32 \pi^{2}} r \rho_{\mathrm{t}}\right]^{1 / 3}(28)$ 
and $\rho_{\mathrm{t}}=\rho_{\mathrm{v}}+\rho_{\mathrm{c}}$ is total (valence plus core) electron charge density, which is determined self-consistently solving the Dirac equation with the potential $V_{\text {eff }}(r)$ (see Ref. [20] for details). The choice $x_{\alpha}=0$ corresponds to the DiracHartree potential, $x_{\alpha}=2 / 3$ gives the Kohn-Sham potential, and $x_{\alpha}=1$ is the Dirac-Slater potential. In Table VII, we present the results of our calculations of the SE contribution to the Lamb shift performed for $x_{\alpha}=0,1 / 3,2 / 3,1$, and related exact data by Sapirstein and Cheng [20]. Our data were obtained by averaging the model SE operator $h^{\mathrm{SE}}$, given by Eq. (22), with the wave function of the valence state $v$ determined from the Dirac equation with the potential $V_{\text {eff }}(r)$. To demonstrate the importance of the nonlocal part of $h^{\mathrm{SE}}$, in addition to the total $\left\langle v\left|h^{\mathrm{SE}}\right| v\right\rangle$ contribution, we present also the local $\left\langle v\left|V_{\text {loc }}^{\mathrm{SE}}\right| v\right\rangle$ part. As one can see from the table, for all atoms the $\left\langle v\left|h^{\mathrm{SE}}\right| v\right\rangle$ values are in a good agreement with the exact results, while the local potential approximation, $\left\langle v\left|V_{\mathrm{loc}}^{\mathrm{SE}}\right| v\right\rangle$, works reasonably well only for low- $Z$ systems.

In Ref. [24], the QED corrections to the transition energies in $\mathrm{Cu}$-like ions have been calculated in the Kohn-Sham potential. In Table VIII we present the SE corrections to the $4 s-4 p_{1 / 2}, 4 s-4 p_{3 / 2}, 4 p_{1 / 2}-4 d_{3 / 2}, 4 p_{3 / 2}-4 d_{3 / 2}$, and $4 p_{3 / 2}-4 d_{5 / 2}$ transition energies obtained by averaging the model SE operator with the wave function of the valence electron. This wave function was calculated by solving the KS equation with the KS potential constructed self-consistently with the $4 \mathrm{~s}$ state. The comparison with the related exact results from Ref. [24] is also given. It can be seen that the model SE operator results are in a very good agreement with the exact results.

Experiments with superheavy elements have triggered a great interest to calculations of the QED effects in superheavy atoms [31, 32, 54-56]. In Ref. [56], the QED contributions to the binding energy of the valence $7 s$ electrons in $\mathrm{Rg}$ $(Z=111)$ and $\mathrm{Cn}(Z=112)$ have been evaluated in a local Dirac-Fock potential. In Table $I X$ we compare the related SE contributions obtained using the model SE operator in the Dirac-Fock method with those by Goidenko [56]. Despite the calculations in the local DF potential are not fully equivalent to the calculations based on the DF equations, the SE contributions to the one-electron binding energies obtained by averaging the model SE operator with the DF wave function of the valence electron as well as by including this operator into the DF equations are in a good agreement with the corresponding Goidenko's results. For comparison, we present also the total DF values which are obtained as the difference between the SE contributions to the total DF energies of the atom and the ion. It is known [57, 58] that for $\mathrm{Rg}$ and $\mathrm{Cn}$ the ionization occurs out of the $6 d_{5 / 2}$ shell instead of the $7 s$ shell. However, for comparison purposes, here we consider the ${ }^{2} S_{1 / 2} \rightarrow^{1} S_{0}$ transition for $\mathrm{Rg}$ and the ${ }^{1} S_{0} \rightarrow^{2} S_{1 / 2}$ transition for $\mathrm{Cn}$. The presented results are also in a reasonable agreement with those based on the Welton method [55] and with the results obtained using a local SE potential [31]. In Table IX, we give also the results of our calculations of the SE corrections to the binding energy of the valence $8 s$ electrons in E119 and E120 and compare them with the values obtained in Ref. [31].

Finally, we applied our model approach to the Li-like ions, for which rigorous QED calculations have been performed. The self-energy screening diagrams for Li-like ions to first order in $1 / Z$ were first evaluated in Ref. [15]. In that paper, the calculations were performed in the Coulomb potential. Later, the same diagrams have been calculated in the Kohn-Sham and core-Hartree potentials [26, 27]. In Table X] we present the results of our calculations of the screened SE corrections in Li-like ions, based on the model SE operator approach, and compare them with the related results from Refs. [26, 27]. In our approach, the screened SE corrections were obtained by calculating the total ion energy with the model SE operator included into the Dirac-Fock (DF) or the Kohn-Sham (KS) equation and subtracting both the related energy evaluated without the model SE operator and the SE contribution evaluated with the H-like wave functions. In case of the KS method, the KS potential was constructed self-consistently with the valence state under consideration. As one can see from the table, the model SE operator results obtained employing the KS and $\mathrm{DF}$ equations are in a fair agreement with the results obtained by the perturbation theory [26, 27]. Therefore, to a good accuracy, the total SE corrections can be obtained by summing the $\mathrm{H}$-like SE contributions and the screened SE corrections evaluated by solving either DF or KS equations with the model SE operator included, as described above.

\section{CONCLUSION}

In this paper we have developed the model QED operator approach to calculations of the Lamb shifts in relativistic atomic systems. With this method, we proposed the model self-energy operator which is given by Eq. (22). This operator can be easily incorporated into any calculations employing the Dirac-Coulomb-Breit Hamiltonian. This was demonstrated by calculating the Lamb shifts in atoms and ions with the use of the model SE operator and comparing the obtained results with corresponding exact QED calculations.

\section{ACKNOWLEDGMENTS}

We thank Andrey Volotka for providing us with details of his calculations of the self-energy screening diagrams performed in Ref. [26]. Valuable discussions with Jan Derezinski, Bogumil Jeziorski, and Jonathan Sapirstein are gratefully acknowledged. This work was supported by RFBR (Grants No. 13-02-00630 and No.11-02-00943-a) and by the Ministry of Education and Science of Russian Federation (Grant No. 8420).

[1] I. P. Grant, Adv. Phys. 19, 747 (1970). 
TABLE I: Self-energy correction for $n s$ states. Labelling $\left(n, n^{\prime}\right)$ denotes the $F_{n n^{\prime}}$ function defined by Eq. (24). $R$ is the root-mean-square charge radius of the nucleus (in fermi). For each $Z$, the upper line shows the point-nucleus result, whereas the lower line displays the extendednucleus result (if different).

\begin{tabular}{|c|c|c|c|c|c|c|c|c|c|c|c|c|c|c|c|c|}
\hline$Z$ & $R$ & $(1,1)$ & $(1,2)$ & $(1,3)$ & $(1,4)$ & $(1,5)$ & $(2,2)$ & $(2,3)$ & $(2,4)$ & $(2,5)$ & $(3,3)$ & $(3,4)$ & $(3,5)$ & $(4,4)$ & $(4,5)$ & $(5,5)$ \\
\hline 10 & 3.005 & 4.6542 & 4.7961 & 4.8145 & 4.8193 & $4.8210(1)$ & 4.8944 & 4.9325 & 4.9437 & 4.9480 & 4.9524 & 4.9677 & 4.9740 & 4.9749 & 4.9824 & 4.9858 \\
\hline 15 & 3.189 & $\begin{array}{l}3.8014 \\
3.8013\end{array}$ & $\begin{array}{l}3.9463 \\
3.9462\end{array}$ & $\begin{array}{l}3.9639 \\
3.9639\end{array}$ & $\begin{array}{l}3.9681 \\
3.9680\end{array}$ & $\begin{array}{l}3.9693 \\
3.9693\end{array}$ & $\begin{array}{l}4.0509 \\
4.0508\end{array}$ & $\begin{array}{l}4.0885 \\
4.0885\end{array}$ & $\begin{array}{l}4.0992 \\
4.0991\end{array}$ & $\begin{array}{l}4.1030 \\
4.1030\end{array}$ & $\begin{array}{l}4.1082 \\
4.1082\end{array}$ & $\begin{array}{l}4.1229 \\
4.1229\end{array}$ & $\begin{array}{l}4.1288 \\
4.1287\end{array}$ & $\begin{array}{l}4.1296 \\
4.1296\end{array}$ & $\begin{array}{l}4.1367 \\
4.1366\end{array}$ & $\begin{array}{l}4.1396 \\
4.1396\end{array}$ \\
\hline 20 & 3.476 & $\begin{array}{l}3.2463 \\
3.2462\end{array}$ & $\begin{array}{l}3.3946 \\
3.3945\end{array}$ & $\begin{array}{l}3.4114 \\
3.4113\end{array}$ & $\begin{array}{l}3.4148 \\
3.4147\end{array}$ & $\begin{array}{l}3.4155 \\
3.4154\end{array}$ & $\begin{array}{l}3.5066 \\
3.5065\end{array}$ & $\begin{array}{l}3.5438 \\
3.5437\end{array}$ & $\begin{array}{l}3.5538 \\
3.5537\end{array}$ & $\begin{array}{l}3.5572 \\
3.5571\end{array}$ & $\begin{array}{l}3.5633 \\
3.5632\end{array}$ & $\begin{array}{l}3.5773 \\
3.5772\end{array}$ & $\begin{array}{l}3.5826 \\
3.5825\end{array}$ & $\begin{array}{l}3.5834 \\
3.5833\end{array}$ & $\begin{array}{l}3.5899 \\
3.5898\end{array}$ & $\begin{array}{l}3.5923 \\
3.5922\end{array}$ \\
\hline 25 & 3.706 & $\begin{array}{l}2.8501 \\
2.8499\end{array}$ & $\begin{array}{l}3.0023 \\
3.0022\end{array}$ & $\begin{array}{l}3.0183 \\
3.0182\end{array}$ & $\begin{array}{l}3.0208 \\
3.0207\end{array}$ & $\begin{array}{l}3.0209 \\
3.0207\end{array}$ & $\begin{array}{l}3.1230 \\
3.1228\end{array}$ & $\begin{array}{l}3.1597 \\
3.1595\end{array}$ & $\begin{array}{l}3.1689 \\
3.1688\end{array}$ & $\begin{array}{l}3.1716 \\
3.1715\end{array}$ & $\begin{array}{l}3.1789 \\
3.1787\end{array}$ & $\begin{array}{l}3.1922 \\
3.1920\end{array}$ & $\begin{array}{l}3.1969 \\
3.1967\end{array}$ & $\begin{array}{l}3.1975 \\
3.1974\end{array}$ & $\begin{array}{l}3.2034 \\
3.2032\end{array}$ & $\begin{array}{l}3.2052 \\
3.2050\end{array}$ \\
\hline 30 & 3.929 & $\begin{array}{l}2.5520 \\
2.5518\end{array}$ & $\begin{array}{l}2.7087 \\
2.7084\end{array}$ & $\begin{array}{l}2.7238 \\
2.7235\end{array}$ & $\begin{array}{l}2.7253 \\
2.7251\end{array}$ & $\begin{array}{l}2.7246 \\
2.7244\end{array}$ & $\begin{array}{l}2.8388 \\
2.8386\end{array}$ & $\begin{array}{l}2.8750 \\
2.8748\end{array}$ & $\begin{array}{l}2.8835 \\
2.8832\end{array}$ & $\begin{array}{l}2.8855 \\
2.8853\end{array}$ & $\begin{array}{l}2.8940 \\
2.8937\end{array}$ & $\begin{array}{l}2.9064 \\
2.9062\end{array}$ & $\begin{array}{l}2.9105 \\
2.9102\end{array}$ & $\begin{array}{l}2.9110 \\
2.9108\end{array}$ & $\begin{array}{l}2.9162 \\
2.9159\end{array}$ & $\begin{array}{l}2.9173 \\
2.9171\end{array}$ \\
\hline 35 & 4.163 & $\begin{array}{l}2.3200 \\
2.3196\end{array}$ & $\begin{array}{l}2.4816 \\
2.4812\end{array}$ & $\begin{array}{l}2.4958 \\
2.4954\end{array}$ & $\begin{array}{l}2.4963 \\
2.4960\end{array}$ & $\begin{array}{l}2.4949 \\
2.4945\end{array}$ & $\begin{array}{l}2.6223 \\
2.6220\end{array}$ & $\begin{array}{l}2.6580 \\
2.6576\end{array}$ & $\begin{array}{l}2.6656 \\
2.6652\end{array}$ & $\begin{array}{l}2.6669 \\
2.6665\end{array}$ & $\begin{array}{l}2.6767 \\
2.6763\end{array}$ & $\begin{array}{l}2.6882 \\
2.6878\end{array}$ & $\begin{array}{l}2.6915 \\
2.6911\end{array}$ & $\begin{array}{l}2.6919 \\
2.6915\end{array}$ & $\begin{array}{l}2.6963 \\
2.6959\end{array}$ & $\begin{array}{l}2.6967 \\
2.6963\end{array}$ \\
\hline 40 & 4.270 & $\begin{array}{l}2.1352 \\
2.1347\end{array}$ & $\begin{array}{l}2.3024 \\
2.3019\end{array}$ & $\begin{array}{l}2.3156 \\
2.3151\end{array}$ & $\begin{array}{l}2.3151 \\
2.3146\end{array}$ & $\begin{array}{l}2.3129 \\
2.3124\end{array}$ & $\begin{array}{l}2.4548 \\
2.4543\end{array}$ & $\begin{array}{l}2.4899 \\
2.4893\end{array}$ & $\begin{array}{l}2.4965 \\
2.4960\end{array}$ & $\begin{array}{l}2.4970 \\
2.4965\end{array}$ & $\begin{array}{l}2.5083 \\
2.5078\end{array}$ & $\begin{array}{l}2.5187 \\
2.5182\end{array}$ & $\begin{array}{l}2.5213 \\
2.5208\end{array}$ & $\begin{array}{l}2.5215 \\
2.5210\end{array}$ & $\begin{array}{l}2.5250 \\
2.5245\end{array}$ & $\begin{array}{l}2.5246 \\
2.5241\end{array}$ \\
\hline 45 & 4.494 & $\begin{array}{l}1.9859 \\
1.9853\end{array}$ & $\begin{array}{l}2.1594 \\
2.1587\end{array}$ & $\begin{array}{l}2.1716 \\
2.1709\end{array}$ & $\begin{array}{l}2.1700 \\
2.1692\end{array}$ & $\begin{array}{l}2.1668 \\
2.1661\end{array}$ & $\begin{array}{l}2.3247 \\
2.3239\end{array}$ & $\begin{array}{l}2.3591 \\
2.3583\end{array}$ & $\begin{array}{l}2.3647 \\
2.3639\end{array}$ & $\begin{array}{l}2.3643 \\
2.3635\end{array}$ & $\begin{array}{l}2.3772 \\
2.3764\end{array}$ & $\begin{array}{l}2.3865 \\
2.3857\end{array}$ & $\begin{array}{l}2.3882 \\
2.3874\end{array}$ & $\begin{array}{l}2.3882 \\
2.3874\end{array}$ & $\begin{array}{l}2.3907 \\
2.3900\end{array}$ & $\begin{array}{l}2.3894 \\
2.3887\end{array}$ \\
\hline 50 & 4.654 & $\begin{array}{l}1.8643 \\
1.8633\end{array}$ & $\begin{array}{l}2.0448 \\
2.0438\end{array}$ & $\begin{array}{l}2.0560 \\
2.0550\end{array}$ & $\begin{array}{l}2.0531 \\
2.0521\end{array}$ & $\begin{array}{l}2.0490 \\
2.0480\end{array}$ & $\begin{array}{l}2.2243 \\
2.2233\end{array}$ & $\begin{array}{l}2.2580 \\
2.2569\end{array}$ & $\begin{array}{l}2.2625 \\
2.2614\end{array}$ & $\begin{array}{l}2.2611 \\
2.2600\end{array}$ & $\begin{array}{l}2.2757 \\
2.2747\end{array}$ & $\begin{array}{l}2.2837 \\
2.2827\end{array}$ & $\begin{array}{l}2.2844 \\
2.2834\end{array}$ & $\begin{array}{l}2.2842 \\
2.2832\end{array}$ & $\begin{array}{l}2.2857 \\
2.2846\end{array}$ & $\begin{array}{l}2.2833 \\
2.2823\end{array}$ \\
\hline 55 & 4.804 & $\begin{array}{l}1.7648 \\
1.7635\end{array}$ & $\begin{array}{l}1.9533 \\
1.9519\end{array}$ & $\begin{array}{l}1.9635 \\
1.9621\end{array}$ & $\begin{array}{l}1.9593 \\
1.9579\end{array}$ & $\begin{array}{l}1.9542 \\
1.9527\end{array}$ & $\begin{array}{l}2.1487 \\
2.1472\end{array}$ & $\begin{array}{l}2.1816 \\
2.1800\end{array}$ & $\begin{array}{l}2.1847 \\
2.1832\end{array}$ & $\begin{array}{l}2.1822 \\
2.1807\end{array}$ & $\begin{array}{l}2.1988 \\
2.1973\end{array}$ & $\begin{array}{l}2.2054 \\
2.2039\end{array}$ & $\begin{array}{l}2.2050 \\
2.2035\end{array}$ & $\begin{array}{l}2.2045 \\
2.2030\end{array}$ & $\begin{array}{l}2.2047 \\
2.2032\end{array}$ & $\begin{array}{l}2.2012 \\
2.1997\end{array}$ \\
\hline 60 & 4.912 & $\begin{array}{l}1.6838 \\
1.6820\end{array}$ & $\begin{array}{l}1.8815 \\
1.8795\end{array}$ & $\begin{array}{l}1.8906 \\
1.8886\end{array}$ & $\begin{array}{l}1.8848 \\
1.8829\end{array}$ & $\begin{array}{l}1.8786 \\
1.8766\end{array}$ & $\begin{array}{l}2.0945 \\
2.0923\end{array}$ & $\begin{array}{l}2.1264 \\
2.1242\end{array}$ & $\begin{array}{l}2.1281 \\
2.1259\end{array}$ & $\begin{array}{l}2.1243 \\
2.1222\end{array}$ & $\begin{array}{l}2.1431 \\
2.1410\end{array}$ & $\begin{array}{l}2.1479 \\
2.1458\end{array}$ & $\begin{array}{l}2.1463 \\
2.1442\end{array}$ & $\begin{array}{l}2.1455 \\
2.1434\end{array}$ & $\begin{array}{l}2.1443 \\
2.1422\end{array}$ & $\begin{array}{l}2.1395 \\
2.1374\end{array}$ \\
\hline 65 & 5.060 & $\begin{array}{l}1.6186 \\
1.6161\end{array}$ & $\begin{array}{l}1.8267 \\
1.8239\end{array}$ & $\begin{array}{l}1.8346 \\
1.8318\end{array}$ & $\begin{array}{l}1.8273 \\
1.8245\end{array}$ & $\begin{array}{l}1.8197 \\
1.8169\end{array}$ & $\begin{array}{l}2.0596 \\
2.0564\end{array}$ & $\begin{array}{l}2.0904 \\
2.0872\end{array}$ & $\begin{array}{l}2.0904 \\
2.0872\end{array}$ & $\begin{array}{l}2.0852 \\
2.0821\end{array}$ & $\begin{array}{l}2.1064 \\
2.1033\end{array}$ & $\begin{array}{l}2.1092 \\
2.1061\end{array}$ & $\begin{array}{l}2.1061 \\
2.1031\end{array}$ & $\begin{array}{l}2.1049 \\
2.1019\end{array}$ & $\begin{array}{l}2.1021 \\
2.0991\end{array}$ & $\begin{array}{l}2.0958 \\
2.0928\end{array}$ \\
\hline 70 & 5.311 & $\begin{array}{l}1.5674 \\
1.5637\end{array}$ & $\begin{array}{l}1.7876 \\
1.7833\end{array}$ & $\begin{array}{l}1.7942 \\
1.7900\end{array}$ & $\begin{array}{l}1.7850 \\
1.7808\end{array}$ & $\begin{array}{l}1.7760 \\
1.7719\end{array}$ & $\begin{array}{l}2.0429 \\
2.0381\end{array}$ & $\begin{array}{l}2.0723 \\
2.0675\end{array}$ & $\begin{array}{l}2.0703 \\
2.0655\end{array}$ & $\begin{array}{l}2.0634 \\
2.0587\end{array}$ & $\begin{array}{l}2.0874 \\
2.0826\end{array}$ & $\begin{array}{l}2.0878 \\
2.0832\end{array}$ & $\begin{array}{l}2.0831 \\
2.0785\end{array}$ & $\begin{array}{l}2.0814 \\
2.0768\end{array}$ & $\begin{array}{l}2.0767 \\
2.0721\end{array}$ & $\begin{array}{l}2.0686 \\
2.0641\end{array}$ \\
\hline 75 & 5.339 & $\begin{array}{l}1.5290 \\
1.5239\end{array}$ & $\begin{array}{l}1.7632 \\
1.7572\end{array}$ & $\begin{array}{l}1.7683 \\
1.7624\end{array}$ & $\begin{array}{l}1.7570 \\
1.7512\end{array}$ & $\begin{array}{l}1.7464 \\
1.7406\end{array}$ & $\begin{array}{l}2.0441 \\
2.0373\end{array}$ & $\begin{array}{l}2.0718 \\
2.0650\end{array}$ & $\begin{array}{l}2.0674 \\
2.0607\end{array}$ & $\begin{array}{l}2.0586 \\
2.0519\end{array}$ & $\begin{array}{l}2.0857 \\
2.0790\end{array}$ & $\begin{array}{l}2.0834 \\
2.0767\end{array}$ & $\begin{array}{l}2.0767 \\
2.0701\end{array}$ & $\begin{array}{l}2.0744 \\
2.0678\end{array}$ & $\begin{array}{l}2.0674 \\
2.0610\end{array}$ & $\begin{array}{l}2.0573 \\
2.0509\end{array}$ \\
\hline 80 & 5.463 & $\begin{array}{l}1.5028 \\
1.4955\end{array}$ & $\begin{array}{l}1.7533 \\
1.7447\end{array}$ & $\begin{array}{l}1.7568 \\
1.7482\end{array}$ & $\begin{array}{l}1.7431 \\
1.7346\end{array}$ & $\begin{array}{l}1.7305 \\
1.7221\end{array}$ & $\begin{array}{l}2.0639 \\
2.0537\end{array}$ & $\begin{array}{l}2.0894 \\
2.0793\end{array}$ & $\begin{array}{l}2.0822 \\
2.0722\end{array}$ & $\begin{array}{l}2.0710 \\
2.0611\end{array}$ & $\begin{array}{l}2.1018 \\
2.0917\end{array}$ & $\begin{array}{l}2.0961 \\
2.0862\end{array}$ & $\begin{array}{l}2.0870 \\
2.0772\end{array}$ & $\begin{array}{l}2.0840 \\
2.0743\end{array}$ & $\begin{array}{l}2.0744 \\
2.0648\end{array}$ & $\begin{array}{l}2.0619 \\
2.0524\end{array}$ \\
\hline 85 & 5.539 & $\begin{array}{l}1.4888 \\
1.4784\end{array}$ & $\begin{array}{l}1.7587 \\
1.7461\end{array}$ & $\begin{array}{l}1.7602 \\
1.7477\end{array}$ & $\begin{array}{l}1.7435 \\
1.7312\end{array}$ & $\begin{array}{l}1.7287 \\
1.7165\end{array}$ & $\begin{array}{l}2.1039 \\
2.0886\end{array}$ & $\begin{array}{l}2.1266 \\
2.1115\end{array}$ & $\begin{array}{l}2.1158 \\
2.1009\end{array}$ & $\begin{array}{l}2.1018 \\
2.0871\end{array}$ & $\begin{array}{l}2.1369 \\
2.1219\end{array}$ & $\begin{array}{l}2.1271 \\
2.1124\end{array}$ & $\begin{array}{l}2.1152 \\
2.1006\end{array}$ & $\begin{array}{l}2.1113 \\
2.0968\end{array}$ & $\begin{array}{l}2.0985 \\
2.0842\end{array}$ & $\begin{array}{l}2.0831 \\
2.0689\end{array}$ \\
\hline 90 & 5.710 & $\begin{array}{l}1.4875 \\
1.4721\end{array}$ & $\begin{array}{l}1.7806 \\
1.7615\end{array}$ & $\begin{array}{l}1.7797 \\
1.7607\end{array}$ & $\begin{array}{l}1.7595 \\
1.7408\end{array}$ & $\begin{array}{l}1.7420 \\
1.7236\end{array}$ & $\begin{array}{l}2.1669 \\
2.1431\end{array}$ & $\begin{array}{l}2.1860 \\
2.1625\end{array}$ & $\begin{array}{l}2.1708 \\
2.1477\end{array}$ & $\begin{array}{l}2.1533 \\
2.1305\end{array}$ & $\begin{array}{l}2.1936 \\
2.1702\end{array}$ & $\begin{array}{l}2.1786 \\
2.1557\end{array}$ & $\begin{array}{l}2.1631 \\
2.1406\end{array}$ & $\begin{array}{l}2.1582 \\
2.1357\end{array}$ & $\begin{array}{l}2.1415 \\
2.1194\end{array}$ & $\begin{array}{l}2.1225 \\
2.1007\end{array}$ \\
\hline 95 & 5.905 & $\begin{array}{l}1.5005 \\
1.4772\end{array}$ & $\begin{array}{l}1.8218 \\
1.7921\end{array}$ & $\begin{array}{l}1.8176 \\
1.7882\end{array}$ & $\begin{array}{l}1.7931 \\
1.7642\end{array}$ & $\begin{array}{l}1.7723 \\
1.7439\end{array}$ & $\begin{array}{l}2.2575 \\
2.2197\end{array}$ & $\begin{array}{l}2.2719 \\
2.2345\end{array}$ & $\begin{array}{l}2.2510 \\
2.2143\end{array}$ & $\begin{array}{l}2.2291 \\
2.1929\end{array}$ & $\begin{array}{l}2.2757 \\
2.2386\end{array}$ & $\begin{array}{l}2.2543 \\
2.2180\end{array}$ & $\begin{array}{l}2.2344 \\
2.1987\end{array}$ & $\begin{array}{l}2.2280 \\
2.1925(1)\end{array}$ & $\begin{array}{l}2.2066 \\
2.1717\end{array}$ & $\begin{array}{l}2.1831 \\
2.1488\end{array}$ \\
\hline 100 & 5.857 & $\begin{array}{l}1.5302 \\
1.4961\end{array}$ & $\begin{array}{l}1.8863 \\
1.8417\end{array}$ & $\begin{array}{l}1.8779 \\
1.8338\end{array}$ & $\begin{array}{l}1.8479 \\
1.8047\end{array}$ & $\begin{array}{l}1.8230 \\
1.7806\end{array}$ & $\begin{array}{l}2.3831 \\
2.3247\end{array}$ & $\begin{array}{l}2.3910 \\
2.3332\end{array}$ & $\begin{array}{l}2.3627 \\
2.3061\end{array}$ & $\begin{array}{l}2.3351 \\
2.2795\end{array}$ & $\begin{array}{l}2.3897 \\
2.3325\end{array}$ & $\begin{array}{l}2.3600 \\
2.3042\end{array}$ & $\begin{array}{l}2.3343 \\
2.2795\end{array}$ & $\begin{array}{l}2.3262 \\
2.2717(1)\end{array}$ & $\begin{array}{l}2.2987 \\
2.2453(1)\end{array}$ & $\begin{array}{l}2.2697 \\
2.2172\end{array}$ \\
\hline 105 & 5.919 & $\begin{array}{l}1.5809 \\
1.5286\end{array}$ & $\begin{array}{l}1.9811 \\
1.9107\end{array}$ & $\begin{array}{l}1.9670 \\
1.8974\end{array}$ & $\begin{array}{l}1.9298 \\
1.8619\end{array}$ & $\begin{array}{l}1.8996 \\
1.8331\end{array}$ & $\begin{array}{l}2.5553 \\
2.4602\end{array}$ & $\begin{array}{l}2.5543 \\
2.4604\end{array}$ & $\begin{array}{l}2.5158 \\
2.4243\end{array}$ & $\begin{array}{l}2.4807 \\
2.3911\end{array}$ & $\begin{array}{l}2.5457 \\
2.4531\end{array}$ & $\begin{array}{l}2.5051 \\
2.4150\end{array}$ & $\begin{array}{l}2.4718 \\
2.3836\end{array}$ & $\begin{array}{l}2.4615 \\
2.3737\end{array}$ & $\begin{array}{l}2.4261 \\
2.3403(1)\end{array}$ & $\begin{array}{l}2.3899 \\
2.3058\end{array}$ \\
\hline 110 & 5.993 & $\begin{array}{l}1.6601 \\
1.5771\end{array}$ & $\begin{array}{l}2.1179 \\
2.0031\end{array}$ & $\begin{array}{l}2.0956 \\
1.9824\end{array}$ & $\begin{array}{l}2.0487 \\
1.9388\end{array}$ & $\begin{array}{l}2.0114 \\
1.9040\end{array}$ & $\begin{array}{l}2.7936 \\
2.6334\end{array}$ & $\begin{array}{l}2.7797 \\
2.6222\end{array}$ & $\begin{array}{l}2.7272 \\
2.5743\end{array}$ & $\begin{array}{l}2.6819 \\
2.5325\end{array}$ & $\begin{array}{l}2.7609 \\
2.6058\end{array}$ & $\begin{array}{l}2.7055 \\
2.5552\end{array}$ & $\begin{array}{l}2.6617 \\
2.5151\end{array}$ & $\begin{array}{l}2.6484 \\
2.5026(1)\end{array}$ & $\begin{array}{l}2.6025 \\
2.4604(2)\end{array}$ & $\begin{array}{l}2.5566 \\
2.4179\end{array}$ \\
\hline 115 & 6.088 & $\begin{array}{l}1.7811 \\
1.6441\end{array}$ & $\begin{array}{l}2.3180 \\
2.1228\end{array}$ & $\begin{array}{l}2.2832 \\
2.0917\end{array}$ & $\begin{array}{l}2.2224 \\
2.0375\end{array}$ & $\begin{array}{l}2.1751 \\
1.9952\end{array}$ & $\begin{array}{l}3.1331 \\
2.8519\end{array}$ & $\begin{array}{l}3.1001 \\
2.8248\end{array}$ & $\begin{array}{l}3.0270 \\
2.7610\end{array}$ & $\begin{array}{l}2.9668 \\
2.7081\end{array}$ & $\begin{array}{l}3.0659 \\
2.7958\end{array}$ & $\begin{array}{l}2.9893 \\
2.7288\end{array}$ & $\begin{array}{l}2.9307 \\
2.6775\end{array}$ & $\begin{array}{l}2.9131 \\
2.6617(1)\end{array}$ & $\begin{array}{l}2.8527 \\
2.6084(1)\end{array}$ & $\begin{array}{l}2.7933 \\
2.5556\end{array}$ \\
\hline 120 & 6.175 & $\begin{array}{l}1.9709 \\
1.7335(1)\end{array}$ & $\begin{array}{l}2.6233 \\
2.2753(1)\end{array}$ & $\begin{array}{l}2.5685 \\
2.2294(1)\end{array}$ & $\begin{array}{l}2.4866(1) \\
2.1613(1)\end{array}$ & $\begin{array}{l}2.4243(1) \\
2.1093(1)\end{array}$ & $\begin{array}{l}3.6437 \\
3.1256(1)\end{array}$ & $\begin{array}{l}3.5804(1) \\
3.0760(1)\end{array}$ & $\begin{array}{l}3.4750(1) \\
2.9909(1)\end{array}$ & $\begin{array}{l}3.3921(1) \\
2.9231(1)\end{array}$ & $\begin{array}{l}3.5219(1) \\
3.0295(1)\end{array}$ & $\begin{array}{l}3.4131 \\
2.9411(1)\end{array}$ & $\begin{array}{l}3.3319 \\
2.8750(1)\end{array}$ & $\begin{array}{l}3.3080 \\
2.8549(2)\end{array}$ & $\begin{array}{l}3.2259 \\
2.7875(1)\end{array}$ & $\begin{array}{l}3.1464 \\
2.7216\end{array}$ \\
\hline
\end{tabular}

[2] J. P. Desclaux, Comput. Phys. Commun. 9, 31 (1975).

[3] V.F. Bratsev, G.B. Deyneka, and I.I. Tupitsyn, Bull.Acad.Sci. USSR, Phys. Ser. 41, 173 (1977).

[4] P. Indelicato and J. P. Desclaux, Phys. Rev. A 42, 5139 (1990).

[5] M.G. Kozlov, S.G. Porsev, and I.I.Tupitsyn, Phys. Rev. Lett. 86, 3260 (2001).

[6] D. A. Glazov, V. M. Shabaev, I. I. Tupitsyn, A. V. Volotka, V. A. Yerokhin, G. Plunien, G. Soff, Phys. Rev. A 70, 062104 (2004).

[7] I. I. Tupitsyn, A. V. Volotka, D. A. Glazov, V. M. Shabaev, G. Plunien, J. R. Crespo López-Urrutia, A. Lapierre, J. Ullrich, Phys. Rev. A 72, 062503 (2005).

[8] V.A. Dzuba, V.V. Flambaum, and O.P. Sushkov, Phys. Lett. A 141, 147 (1989).

[9] S.A. Blundell, W.R. Johnson and J. Sapirstein, Phys. Rev. Lett., 65, 1411 (1990); S.A. Blundell, J. Sapirstein, and W.R. Johnson, Phys. Rev. D 45, 1602 (1992).

[10] P. Indelicato and E. Lindroth, Phys. Rev. A 46, 2426 (1992).
[11] A.Ynnerman, J.James, I.Lindgren, H.Persson and S.Salomonson, Phys. Rev. A 50, 4671 (1994).

[12] M. S. Safronova, W. R. Johnson, and A. Derevianko, Phys. Rev. A 60, $4476(1999)$

[13] S. G. Porsev, K. Beloy, and A. Derevianko, Phys. Rev. Lett. 102, 181601 (2009); Phys. Rev. D 82, 036008 (2010).

[14] V. A. Dzuba, J. C. Berengut, V. V. Flambaum, B. Roberts, Phys. Rev. Lett. 109, 203003 (2012).

[15] V. A. Yerokhin, A. N. Artemyev, T. Beier, G. Plunien, V. M. Shabaev, and G. Soff Phys. Rev. A 60, 3522 (1999).

[16] A. N. Artemyev, V. M. Shabaev, V. A. Yerokhin, G. Plunien, and G. Soff Phys. Rev. A 71, 062104 (2005).

[17] V.M. Shabaev, Physics-Uspekhi 51, 1175 (2008).

[18] D.A. Glazov, Y.S. Kozhedub, A.V. Maiorova, V.M. Shabaev, I.I. Tupitsyn, A.V. Volotka, C. Kozhuharov, G. Plunien, Th. Stóhlker, Hyperfine Interactions 199, 71 (2011).

[19] A.V. Volotka, D.A. Glazov, O.V. Andreev, V.M. Shabaev, I.I. 
TABLE II: Self-energy correction for $n p_{1 / 2}$ states.

\begin{tabular}{|c|c|c|c|c|c|c|c|c|c|c|c|}
\hline$Z$ & $R$ & $(2,2)$ & $(2,3)$ & $(2,4)$ & $(2,5)$ & $(3,3)$ & $(3,4)$ & $(3,5)$ & $(4,4)$ & $(4,5)$ & $(5,5)$ \\
\hline 10 & 3.005 & -0.1148 & -0.0962 & -0.0946 & -0.0946 & -0.1020 & -0.0941 & -0.0923 & $-0.0964(1)$ & -0.0921 & -0.0932 \\
\hline 15 & 3.189 & -0.1045 & -0.0851 & -0.0833 & -0.0831 & -0.0901 & -0.0818 & -0.0799 & -0.0837 & -0.0794 & -0.0803 \\
\hline 20 & 3.476 & -0.0925 & -0.0721 & -0.0699 & -0.0696 & -0.0760 & -0.0674 & -0.0653 & -0.0690 & -0.0644 & -0.0653 \\
\hline 25 & 3.706 & -0.0791 & -0.0576 & -0.0550 & -0.0545 & -0.0603 & -0.0512 & -0.0489 & -0.0525 & -0.0477 & -0.0484 \\
\hline 30 & 3.929 & -0.0643 & -0.0416 & -0.0386 & -0.0379 & -0.0431 & -0.0336 & -0.0310 & -0.0344 & -0.0295 & -0.0299 \\
\hline 35 & 4.163 & -0.0483 & -0.0242 & -0.0207 & -0.0199 & -0.0244 & -0.0144 & -0.0116 & -0.0148 & -0.0097 & -0.0099 \\
\hline 40 & 4.270 & -0.0310 & -0.0054 & -0.0014 & -0.0003 & -0.0042 & 0.0063 & 0.0094 & 0.0063 & 0.0117 & 0.0116 \\
\hline 45 & 4.494 & -0.0123 & 0.0150 & 0.0196 & 0.0208 & 0.0177 & 0.0287 & 0.0321 & 0.0291 & 0.0347 & 0.0347 \\
\hline 50 & 4.654 & 0.0080 & 0.0371 & 0.0423 & 0.0438 & 0.0414 & 0.0529 & 0.0566 & 0.0538 & 0.0595 & 0.0597 \\
\hline 55 & 4.804 & 0.0303 & 0.0614 & 0.0672 & 0.0689 & 0.0672 & 0.0793 & 0.0833 & 0.0805 & 0.0864 & 0.0867 \\
\hline 60 & 4.912 & $\begin{array}{l}0.0548 \\
0.0547\end{array}$ & $\begin{array}{l}0.0881 \\
0.0881\end{array}$ & $\begin{array}{l}0.0946 \\
0.0946\end{array}$ & $\begin{array}{l}0.0965 \\
0.0965\end{array}$ & $\begin{array}{l}0.0956 \\
0.0955\end{array}$ & $\begin{array}{l}0.1083 \\
0.1082\end{array}$ & $\begin{array}{l}0.1125 \\
0.1125\end{array}$ & $\begin{array}{l}0.1098 \\
0.1098\end{array}$ & $\begin{array}{l}0.1158 \\
0.1157\end{array}$ & $\begin{array}{l}0.1161 \\
0.1161\end{array}$ \\
\hline 65 & 5.060 & $\begin{array}{l}0.0820 \\
0.0819\end{array}$ & $\begin{array}{l}0.1178 \\
0.1177\end{array}$ & $\begin{array}{l}0.1250 \\
0.1249\end{array}$ & $\begin{array}{l}0.1271 \\
0.1270\end{array}$ & $\begin{array}{l}0.1271 \\
0.1270\end{array}$ & $\begin{array}{l}0.1402 \\
0.1401\end{array}$ & $\begin{array}{l}0.1448 \\
0.1447\end{array}$ & $\begin{array}{l}0.1421 \\
0.1420\end{array}$ & $\begin{array}{l}0.1481 \\
0.1480\end{array}$ & $\begin{array}{l}0.1485 \\
0.1484\end{array}$ \\
\hline 70 & 5.311 & $\begin{array}{l}0.1127 \\
0.1126\end{array}$ & $\begin{array}{l}0.1512 \\
0.1510\end{array}$ & $\begin{array}{l}0.1591 \\
0.1590\end{array}$ & $\begin{array}{l}0.1614 \\
0.1612\end{array}$ & $\begin{array}{l}0.1623 \\
0.1621\end{array}$ & $\begin{array}{l}0.1760 \\
0.1758\end{array}$ & $\begin{array}{l}0.1807 \\
0.1805\end{array}$ & $\begin{array}{l}0.1781 \\
0.1778\end{array}$ & $\begin{array}{l}0.1840 \\
0.1838\end{array}$ & $\begin{array}{l}0.1844 \\
0.1841\end{array}$ \\
\hline 75 & 5.339 & $\begin{array}{l}0.1477 \\
0.1474\end{array}$ & $\begin{array}{l}0.1891 \\
0.1888\end{array}$ & $\begin{array}{l}0.1979 \\
0.1975\end{array}$ & $\begin{array}{l}0.2002 \\
0.1999\end{array}$ & $\begin{array}{l}0.2023 \\
0.2020\end{array}$ & $\begin{array}{l}0.2164 \\
0.2160\end{array}$ & $\begin{array}{l}0.2213 \\
0.2209\end{array}$ & $\begin{array}{l}0.2186 \\
0.2182\end{array}$ & $\begin{array}{l}0.2244 \\
0.2240\end{array}$ & $\begin{array}{l}0.2246 \\
0.2242\end{array}$ \\
\hline 80 & 5.463 & $\begin{array}{l}0.1882 \\
0.1877\end{array}$ & $\begin{array}{l}0.2329 \\
0.2323\end{array}$ & $\begin{array}{l}0.2424 \\
0.2418\end{array}$ & $\begin{array}{l}0.2448 \\
0.2441\end{array}$ & $\begin{array}{l}0.2483 \\
0.2476\end{array}$ & $\begin{array}{l}0.2626 \\
0.2619\end{array}$ & $\begin{array}{l}0.2677 \\
0.2670\end{array}$ & $\begin{array}{l}0.2649 \\
0.2642\end{array}$ & $\begin{array}{l}0.2704 \\
0.2697\end{array}$ & $\begin{array}{l}0.2703 \\
0.2696\end{array}$ \\
\hline 85 & 5.539 & $\begin{array}{l}0.2359 \\
0.2349\end{array}$ & $\begin{array}{l}0.2843 \\
0.2832\end{array}$ & $\begin{array}{l}0.2944 \\
0.2933\end{array}$ & $\begin{array}{l}0.2967 \\
0.2955\end{array}$ & $\begin{array}{l}0.3020 \\
0.3008\end{array}$ & $\begin{array}{l}0.3165 \\
0.3152\end{array}$ & $\begin{array}{l}0.3215 \\
0.3202\end{array}$ & $\begin{array}{l}0.3185 \\
0.3173\end{array}$ & $\begin{array}{l}0.3236 \\
0.3223\end{array}$ & $\begin{array}{l}0.3230 \\
0.3217\end{array}$ \\
\hline 90 & 5.710 & $\begin{array}{l}0.2931 \\
0.2912\end{array}$ & $\begin{array}{l}0.3457 \\
0.3436\end{array}$ & $\begin{array}{l}0.3563 \\
0.3542\end{array}$ & $\begin{array}{l}0.3583 \\
0.3562\end{array}$ & $\begin{array}{l}0.3660 \\
0.3637\end{array}$ & $\begin{array}{l}0.3803 \\
0.3780\end{array}$ & $\begin{array}{l}0.3850 \\
0.3827\end{array}$ & $\begin{array}{l}0.3819 \\
0.3795\end{array}$ & $\begin{array}{l}0.3862 \\
0.3838\end{array}$ & $\begin{array}{l}0.3849 \\
0.3825\end{array}$ \\
\hline 95 & 5.905 & $\begin{array}{l}0.3633 \\
0.3597\end{array}$ & $\begin{array}{l}0.4205 \\
0.4166\end{array}$ & $\begin{array}{l}0.4315 \\
0.4275\end{array}$ & $\begin{array}{l}0.4329 \\
0.4288\end{array}$ & $\begin{array}{l}0.4438 \\
0.4394\end{array}$ & $\begin{array}{l}0.4575 \\
0.4531\end{array}$ & $\begin{array}{l}0.4616 \\
0.4572\end{array}$ & $\begin{array}{l}0.4583 \\
0.4538\end{array}$ & $\begin{array}{l}0.4613 \\
0.4569\end{array}$ & $\begin{array}{l}0.4589 \\
0.4544\end{array}$ \\
\hline 100 & 5.857 & $\begin{array}{l}0.4517 \\
0.4450\end{array}$ & $\begin{array}{l}0.5143 \\
0.5070\end{array}$ & $\begin{array}{l}0.5251 \\
0.5177\end{array}$ & $\begin{array}{l}0.5254 \\
0.5180\end{array}$ & $\begin{array}{l}0.5408 \\
0.5327\end{array}$ & $\begin{array}{l}0.5533 \\
0.5452\end{array}$ & $\begin{array}{l}0.5563 \\
0.5482\end{array}$ & $\begin{array}{l}0.5525 \\
0.5443\end{array}$ & $\begin{array}{l}0.5538 \\
0.5456\end{array}$ & $\begin{array}{l}0.5498 \\
0.5416\end{array}$ \\
\hline 105 & 5.919 & $\begin{array}{l}0.5669 \\
0.5537\end{array}$ & $\begin{array}{l}0.6355 \\
0.6211\end{array}$ & $\begin{array}{l}0.6454 \\
0.6308\end{array}$ & $\begin{array}{l}0.6438 \\
0.6294\end{array}$ & $\begin{array}{l}0.6655 \\
0.6498\end{array}$ & $\begin{array}{l}0.6758 \\
0.6600\end{array}$ & $\begin{array}{l}0.6768 \\
0.6610\end{array}$ & $\begin{array}{l}0.6725 \\
0.6566\end{array}$ & $\begin{array}{l}0.6711 \\
0.6552\end{array}$ & $\begin{array}{l}0.6645 \\
0.6487\end{array}$ \\
\hline 110 & 5.993 & $\begin{array}{l}0.7231 \\
0.6961\end{array}$ & $\begin{array}{l}0.7984 \\
0.7689\end{array}$ & $\begin{array}{l}0.8059 \\
0.7763\end{array}$ & $\begin{array}{l}0.8012 \\
0.7719\end{array}$ & $\begin{array}{l}0.8322 \\
0.8002\end{array}$ & $\begin{array}{l}0.8385 \\
0.8064\end{array}$ & $\begin{array}{l}0.8361 \\
0.8043\end{array}$ & $\begin{array}{l}0.8311 \\
0.7989(1)\end{array}$ & $\begin{array}{l}0.8254 \\
0.7936\end{array}$ & $\begin{array}{l}0.8150 \\
0.7834\end{array}$ \\
\hline 115 & 6.088 & $\begin{array}{l}0.9468 \\
0.8881\end{array}$ & $\begin{array}{l}1.0292 \\
0.9656\end{array}$ & $\begin{array}{l}1.0314 \\
0.9681\end{array}$ & $\begin{array}{l}1.0212 \\
0.9587\end{array}$ & $\begin{array}{l}1.0668 \\
0.9983\end{array}$ & $\begin{array}{l}1.0659 \\
0.9977\end{array}$ & $\begin{array}{l}1.0575 \\
0.9902\end{array}$ & $\begin{array}{l}1.0513 \\
0.9834(1)\end{array}$ & $\begin{array}{l}1.0388 \\
0.9719(1)\end{array}$ & $\begin{array}{l}1.0222 \\
0.9561\end{array}$ \\
\hline 120 & 6.175 & $\begin{array}{l}1.2926 \\
1.1559\end{array}$ & $\begin{array}{l}1.3816 \\
1.2352\end{array}$ & $\begin{array}{l}1.3726 \\
1.2280\end{array}$ & $\begin{array}{l}1.3522 \\
1.2102\end{array}$ & $\begin{array}{l}1.4219 \\
1.2658\end{array}$ & $\begin{array}{l}1.4074 \\
1.2532(1)\end{array}$ & $\begin{array}{l}1.3881 \\
1.2369(1)\end{array}$ & $\begin{array}{l}1.3798 \\
1.2275(2)\end{array}$ & $\begin{array}{l}1.3557 \\
1.2064(2)\end{array}$ & $\begin{array}{l}1.3286 \\
1.1819\end{array}$ \\
\hline
\end{tabular}

Tupitsyn, and G. Plunien, Phys. Rev. Lett. 108, 073001 (2012). [20] J. Sapirstein and K. T. Cheng Phys. Rev. A 66, 042501 (2002). [21] J. Sapirstein and K. T. Cheng Phys. Rev. A 68, 042111 (2003).

[22] V. M. Shabaev, K. Pachucki, I. I. Tupitsyn, and V. A. Yerokhin, Phys. Rev. Lett. 94, 213002 (2005).

[23] V. M. Shabaev, I. I. Tupitsyn, K. Pachucki, G. Plunien, and V. A. Yerokhin Phys. Rev. A 72, 062105 (2005).

[24] M. H. Chen, K. T. Cheng, W. R. Johnson, and J. Sapirstein, Phys. Rev. A 74, 042510 (2006).

[25] A.N. Artemyev, V.M. Shabaev, I.I. Tupitsyn, G. Plunien, V.A. Yerokhin, Phys. Rev. Lett., 98, 173004 (2007).

[26] Y. S. Kozhedub, A. V. Volotka, A. N. Artemyev, D. A. Glazov, G. Plunien, V. M. Shabaev, I. I. Tupitsyn, and Th. Stöhlker, Phys. Rev. A 81, 042513 (2010).

[27] J. Sapirstein and K. T. Cheng Phys. Rev. A 83, 012504 (2011).

[28] P. Pyykko and L.-B. Zhao, J. Phys. B 36, 1469 (2003).

[29] I. Draganic, J. R. Crespo López-Urrutia, R. DuBois, S. Fritzsche, V. M. Shabaev, R. S. Orts, I. I. Tupitsyn, Y. Zou, and J. Ullrich, Phys. Rev. Lett. 91, 183001 (2003).

[30] V.V. Flambaum and J.S.M. Ginges, Phys. Rev. A 72, 052115 (2005).

[31] C. Thierfelder and P. Schwerdtfeger, Phys. Rev. A 82, 062503 (2010).

[32] P. Pyykko, Chemical Reviews 112, 371 (2012).

[33] I.I. Tupitsyn and E.V. Berseneva, Optics and Spectroscopy 114, 682 (2013).
[34] J.A. Lowe, C.T. Chantler, and I.P. Grant, Radiation Physics and Chemistry 85, 118 (2013).

[35] B.M. Roberts, V.A. Dzuba, and V.V. Flambaum, Phys. Rev. A 87, 054502 (2013).

[36] T.A. Welton, Phys. Rev.74, 1157 (1948).

[37] V.M. Shabaev, J. Phys. B 26, 4703 (1993).

[38] V.M. Shabaev, Phys. Rep. 356, 119 (2002).

[39] M.H. Mittleman, Phys. Rev. A 5, 2395 (1972).

[40] J. Sucher, Phys. Rev. A 22, 348 (1980).

[41] P.J. Mohr, G. Plunien, and G. Soff, Phys. Rep. 293, 227 (1998).

[42] L.W. Fullerton and G.A. Rinker, Jr., Phys. Rev. A 13, 1283 (1976).

[43] G. Soff and P. J. Mohr, Phys. Rev. A 38, 5066 (1988).

[44] N.L. Manakov, A.A. Nekipelov, A.G. Fainshtein, Sov. Phys. JETP 68, 673 (1989).

[45] H. Persson, I. Lindgren, S. Salomonson, and P. Sunnergren, Phys. Rev. A 48, 2772 (1993).

[46] A.G. Fainshtein, N.L. Manakov, and A.A. Nekipelov, J. Phys. B 24, 559 (1991).

[47] P.J. Mohr, Phys. Rev. A 46, 4421 (1992).

[48] P.J. Mohr and Y.-K. Kim, Phys. Rev. A 45, 2727 (1992).

[49] T. Beier, P.J. Mohr, H. Persson, and G. Soff, Phys. Rev. A 58, 954 (1998).

[50] V.A. Yerokhin and V.M. Shabaev, Phys. Rev. A 60, 800 (1999).

[51] V. A. Yerokhin, K. Pachucki, and V. M. Shabaev, Phys. Rev. A 72, 042502 (2005). 
TABLE III: Self-energy correction for $n p_{3 / 2}$ states.

\begin{tabular}{|c|c|c|c|c|c|c|c|c|c|c|c|}
\hline$Z$ & $R$ & $(2,2)$ & $(2,3)$ & $(2,4)$ & $(2,5)$ & $(3,3)$ & $(3,4)$ & $(3,5)$ & $(4,4)$ & $(4,5)$ & $(5,5)$ \\
\hline 10 & 3.005 & 0.1304 & 0.1335 & 0.1316 & 0.1301 & 0.1421 & 0.1454 & 0.1457 & 0.1474 & 0.1496 & 0.1503 \\
\hline 15 & 3.189 & 0.1366 & 0.1399 & 0.1380 & 0.1365 & 0.1490 & 0.1525 & 0.1527 & 0.1546 & 0.1569 & 0.1576 \\
\hline 20 & 3.476 & 0.1438 & 0.1473 & 0.1455 & 0.1440 & 0.1572 & 0.1607 & 0.1610 & 0.1630 & 0.1654 & 0.1662 \\
\hline 25 & 3.706 & 0.1519 & 0.1556 & 0.1537 & 0.1523 & 0.1663 & 0.1699 & 0.1702 & 0.1725 & 0.1749 & 0.1758 \\
\hline 30 & 3.929 & 0.1606 & 0.1646 & 0.1627 & 0.1612 & 0.1761 & 0.1799 & 0.1803 & 0.1827 & 0.1852 & 0.1861 \\
\hline 35 & 4.163 & 0.1699 & 0.1741 & 0.1722 & 0.1706 & 0.1866 & 0.1906 & 0.1909 & 0.1936 & 0.1962 & 0.1972 \\
\hline 40 & 4.270 & 0.1796 & 0.1841 & 0.1821 & 0.1805 & 0.1977 & 0.2019 & 0.2022 & 0.2052 & 0.2078 & 0.2090 \\
\hline 45 & 4.494 & 0.1897 & 0.1945 & 0.1925 & 0.1908 & 0.2093 & 0.2137 & 0.2140 & 0.2173 & 0.2200 & 0.2213 \\
\hline 50 & 4.654 & 0.2001 & 0.2053 & 0.2032 & 0.2015 & 0.2214 & 0.2260 & 0.2264 & 0.2299 & 0.2328 & 0.2341 \\
\hline 55 & 4.804 & 0.2107 & 0.2165 & 0.2143 & 0.2124 & 0.2340 & 0.2388 & 0.2392 & 0.2431 & 0.2461 & 0.2475 \\
\hline 60 & 4.912 & 0.2216 & 0.2279 & 0.2256 & 0.2237 & 0.2471 & 0.2521 & 0.2525 & 0.2568 & 0.2599 & 0.2615 \\
\hline 65 & 5.060 & 0.2328 & 0.2397 & 0.2373 & 0.2353 & 0.2605 & 0.2660 & 0.2663 & 0.2710 & 0.2743 & 0.2760 \\
\hline 70 & 5.311 & 0.2441 & 0.2517 & 0.2493 & 0.2472 & 0.2745 & 0.2803 & 0.2807 & 0.2858 & 0.2892 & 0.2910 \\
\hline 75 & 5.339 & $\begin{array}{l}0.2556 \\
0.2555\end{array}$ & $\begin{array}{l}0.2641 \\
0.2640\end{array}$ & $\begin{array}{l}0.2616 \\
0.2615\end{array}$ & $\begin{array}{l}0.2594 \\
0.2593\end{array}$ & $\begin{array}{l}0.2889 \\
0.2888\end{array}$ & $\begin{array}{l}0.2951 \\
0.2950\end{array}$ & $\begin{array}{l}0.2955 \\
0.2954\end{array}$ & $\begin{array}{l}0.3011 \\
0.3010\end{array}$ & $\begin{array}{l}0.3047 \\
0.3046\end{array}$ & $\begin{array}{l}0.3067 \\
0.3066\end{array}$ \\
\hline 80 & 5.463 & $\begin{array}{l}0.2672 \\
0.2671\end{array}$ & $\begin{array}{l}0.2767 \\
0.2766\end{array}$ & $\begin{array}{l}0.2742 \\
0.2741\end{array}$ & $\begin{array}{l}0.2718 \\
0.2717\end{array}$ & $\begin{array}{l}0.3038 \\
0.3036\end{array}$ & $\begin{array}{l}0.3105 \\
0.3103\end{array}$ & $\begin{array}{l}0.3109 \\
0.3107\end{array}$ & $\begin{array}{l}0.3171 \\
0.3169\end{array}$ & $\begin{array}{l}0.3208 \\
0.3207\end{array}$ & $\begin{array}{l}0.3230 \\
0.3228\end{array}$ \\
\hline 85 & 5.539 & $\begin{array}{l}0.2789 \\
0.2787\end{array}$ & $\begin{array}{l}0.2896 \\
0.2894\end{array}$ & $\begin{array}{l}0.2871 \\
0.2869\end{array}$ & $\begin{array}{l}0.2846 \\
0.2844\end{array}$ & $\begin{array}{l}0.3191 \\
0.3189\end{array}$ & $\begin{array}{l}0.3264 \\
0.3261\end{array}$ & $\begin{array}{l}0.3269 \\
0.3266\end{array}$ & $\begin{array}{l}0.3336 \\
0.3333\end{array}$ & $\begin{array}{l}0.3376 \\
0.3373\end{array}$ & $\begin{array}{l}0.3399 \\
0.3396\end{array}$ \\
\hline 90 & 5.710 & $\begin{array}{l}0.2907 \\
0.2904\end{array}$ & $\begin{array}{l}0.3028 \\
0.3024\end{array}$ & $\begin{array}{l}0.3003 \\
0.3000\end{array}$ & $\begin{array}{l}0.2977 \\
0.2973\end{array}$ & $\begin{array}{l}0.3350 \\
0.3346\end{array}$ & $\begin{array}{l}0.3428 \\
0.3424\end{array}$ & $\begin{array}{l}0.3434 \\
0.3430\end{array}$ & $\begin{array}{l}0.3507 \\
0.3503\end{array}$ & $\begin{array}{l}0.3550 \\
0.3545\end{array}$ & $\begin{array}{l}0.3575 \\
0.3570\end{array}$ \\
\hline 95 & 5.905 & $\begin{array}{l}0.3024 \\
0.3020\end{array}$ & $\begin{array}{l}0.3161 \\
0.3156\end{array}$ & $\begin{array}{l}0.3138 \\
0.3132\end{array}$ & $\begin{array}{l}0.3111 \\
0.3105\end{array}$ & $\begin{array}{l}0.3512 \\
0.3506\end{array}$ & $\begin{array}{l}0.3598 \\
0.3592\end{array}$ & $\begin{array}{l}0.3605 \\
0.3598\end{array}$ & $\begin{array}{l}0.3685 \\
0.3678\end{array}$ & $\begin{array}{l}0.3730 \\
0.3723\end{array}$ & $\begin{array}{l}0.3757 \\
0.3750\end{array}$ \\
\hline 100 & 5.857 & $\begin{array}{l}0.3141 \\
0.3135\end{array}$ & $\begin{array}{l}0.3297 \\
0.3289\end{array}$ & $\begin{array}{l}0.3275 \\
0.3267\end{array}$ & $\begin{array}{l}0.3247 \\
0.3239\end{array}$ & $\begin{array}{l}0.3679 \\
0.3670\end{array}$ & $\begin{array}{l}0.3773 \\
0.3764\end{array}$ & $\begin{array}{l}0.3781 \\
0.3771\end{array}$ & $\begin{array}{l}0.3868 \\
0.3858\end{array}$ & $\begin{array}{l}0.3917 \\
0.3906\end{array}$ & $\begin{array}{l}0.3946 \\
0.3935\end{array}$ \\
\hline 105 & 5.919 & $\begin{array}{l}0.3256 \\
0.3248(1)\end{array}$ & $\begin{array}{l}0.3433 \\
0.3421\end{array}$ & $\begin{array}{l}0.3414 \\
0.3402\end{array}$ & $\begin{array}{l}0.3385 \\
0.3373\end{array}$ & $\begin{array}{l}0.3849 \\
0.3836\end{array}$ & $\begin{array}{l}0.3953 \\
0.3938\end{array}$ & $\begin{array}{l}0.3963 \\
0.3948\end{array}$ & $\begin{array}{l}0.4056 \\
0.4041\end{array}$ & $\begin{array}{l}0.4109 \\
0.4093\end{array}$ & $\begin{array}{l}0.4140 \\
0.4124\end{array}$ \\
\hline 110 & 5.993 & $\begin{array}{l}0.3368 \\
0.3356(1)\end{array}$ & $\begin{array}{l}0.3567 \\
0.3552\end{array}$ & $\begin{array}{l}0.3552 \\
0.3535\end{array}$ & $\begin{array}{l}0.3523 \\
0.3506\end{array}$ & $\begin{array}{l}0.4020 \\
0.4002\end{array}$ & $\begin{array}{l}0.4134 \\
0.4113\end{array}$ & $\begin{array}{l}0.4146 \\
0.4125\end{array}$ & $\begin{array}{l}0.4247 \\
0.4225\end{array}$ & $\begin{array}{l}0.4304 \\
0.4281\end{array}$ & $\begin{array}{l}0.4338 \\
0.4315\end{array}$ \\
\hline 115 & 6.088 & $\begin{array}{l}0.3473 \\
0.3457(1)\end{array}$ & $\begin{array}{l}0.3698 \\
0.3676\end{array}$ & $\begin{array}{l}0.3688 \\
0.3665\end{array}$ & $\begin{array}{l}0.3660 \\
0.3635\end{array}$ & $\begin{array}{l}0.4189 \\
0.4163\end{array}$ & $\begin{array}{l}0.4314 \\
0.4285\end{array}$ & $\begin{array}{l}0.4329 \\
0.4300\end{array}$ & $\begin{array}{l}0.4437 \\
0.4407\end{array}$ & $\begin{array}{l}0.4498 \\
0.4467\end{array}$ & $\begin{array}{l}0.4535(1) \\
0.4502(1)\end{array}$ \\
\hline 120 & 6.175 & $\begin{array}{l}0.3567 \\
0.3548(1)\end{array}$ & $\begin{array}{l}0.3819 \\
0.3792\end{array}$ & $\begin{array}{l}0.3816 \\
0.3786\end{array}$ & $\begin{array}{l}0.3789 \\
0.3757\end{array}$ & $\begin{array}{l}0.4348 \\
0.4316(1)\end{array}$ & $\begin{array}{l}0.4484 \\
0.4448\end{array}$ & $\begin{array}{l}0.4504 \\
0.4466\end{array}$ & $\begin{array}{l}0.4617 \\
0.4580\end{array}$ & $\begin{array}{l}0.4683 \\
0.4643\end{array}$ & $\begin{array}{l}0.4722(1) \\
0.4681(1)\end{array}$ \\
\hline
\end{tabular}

TABLE IV: Self-energy correction for $n d_{3 / 2}$ states.

\begin{tabular}{|c|c|c|c|c|c|c|c|}
\hline$Z$ & $R$ & $(3,3)$ & $(3,4)$ & $(3,5)$ & $(4,4)$ & $(4,5)$ & $(5,5)$ \\
\hline 10 & 3.005 & $-0.0427(1)$ & -0.0352 & $-0.0344(1)$ & -0.0407 & -0.0371 & $-0.0395(1)$ \\
\hline 15 & 3.189 & -0.0424 & -0.0349 & -0.0341 & -0.0403 & -0.0368 & -0.0391 \\
\hline 20 & 3.476 & -0.0420 & -0.0345 & -0.0337 & -0.0399 & -0.0363 & -0.0387 \\
\hline 25 & 3.706 & -0.0415 & -0.0340 & -0.0332 & -0.0393 & -0.0358 & -0.0381 \\
\hline 30 & 3.929 & -0.0410 & -0.0334 & -0.0327 & -0.0387 & -0.0351 & -0.0374 \\
\hline 35 & 4.163 & -0.0404 & -0.0328 & -0.0320 & -0.0379 & -0.0343 & -0.0366 \\
\hline 40 & 4.270 & -0.0396 & -0.0320 & -0.0313 & -0.0371 & -0.0334 & -0.0356 \\
\hline 45 & 4.494 & -0.0388 & -0.0310 & -0.0304 & -0.0360 & -0.0323 & -0.0345 \\
\hline 50 & 4.654 & -0.0378 & -0.0300 & -0.0293 & -0.0348 & -0.0310 & -0.0331 \\
\hline 55 & 4.804 & -0.0366 & -0.0287 & -0.0280 & -0.0334 & -0.0295 & -0.0316 \\
\hline 60 & 4.912 & -0.0353 & -0.0272 & -0.0266 & -0.0317 & -0.0277 & -0.0298 \\
\hline 65 & 5.060 & -0.0338 & -0.0255 & -0.0249 & -0.0298 & -0.0257 & -0.0276 \\
\hline 70 & 5.311 & -0.0321 & -0.0236 & -0.0229 & -0.0276 & -0.0233 & -0.0252 \\
\hline 75 & 5.339 & -0.0302 & -0.0213 & -0.0206 & -0.0251 & -0.0206 & -0.0223 \\
\hline 80 & 5.463 & -0.0279 & -0.0187 & -0.0180 & -0.0221 & -0.0174 & -0.0190 \\
\hline 85 & 5.539 & -0.0254 & -0.0157 & -0.0149 & -0.0188 & -0.0137 & -0.0152 \\
\hline 90 & 5.710 & -0.0225 & -0.0123 & -0.0114 & -0.0149 & -0.0095 & -0.0108 \\
\hline 95 & 5.905 & -0.0192 & -0.0083 & -0.0073 & -0.0104 & -0.0046 & -0.0058 \\
\hline 100 & 5.857 & -0.0154 & -0.0037 & -0.0026 & -0.0053 & 0.0010 & 0.0001 \\
\hline 105 & 5.919 & $\begin{array}{l}-0.0111 \\
-0.0112\end{array}$ & $\begin{array}{l}0.0015 \\
0.0014\end{array}$ & $\begin{array}{l}0.0029 \\
0.0028\end{array}$ & $\begin{array}{l}0.0006 \\
0.0005\end{array}$ & $\begin{array}{l}0.0074 \\
0.0073\end{array}$ & $\begin{array}{l}0.0068 \\
0.0067\end{array}$ \\
\hline 110 & 5.993 & $\begin{array}{l}-0.0062 \\
-0.0063\end{array}$ & $\begin{array}{l}0.0074 \\
0.0073\end{array}$ & $\begin{array}{l}0.0091 \\
0.0090\end{array}$ & $\begin{array}{l}0.0074 \\
0.0072\end{array}$ & $\begin{array}{l}0.0148 \\
0.0146\end{array}$ & $\begin{array}{l}0.0145 \\
0.0143\end{array}$ \\
\hline 115 & 6.088 & $\begin{array}{l}-0.0007 \\
-0.0009\end{array}$ & $\begin{array}{l}0.0142 \\
0.0139\end{array}$ & $\begin{array}{l}0.0163 \\
0.0160\end{array}$ & $\begin{array}{l}0.0151 \\
0.0148\end{array}$ & $\begin{array}{l}0.0232 \\
0.0229\end{array}$ & $\begin{array}{l}0.0232 \\
0.0229\end{array}$ \\
\hline 120 & 6.175 & $\begin{array}{l}0.0055 \\
0.0051(1)\end{array}$ & $\begin{array}{l}0.0219 \\
0.0214\end{array}$ & $\begin{array}{l}0.0245 \\
0.0239\end{array}$ & $\begin{array}{l}0.0238 \\
0.0232\end{array}$ & $\begin{array}{l}0.0328 \\
0.0321\end{array}$ & $\begin{array}{l}0.0332(1) \\
0.0324(1)\end{array}$ \\
\hline
\end{tabular}


TABLE V: Self-energy correction for $n d_{5 / 2}$ states.

\begin{tabular}{|c|c|c|c|c|c|c|c|}
\hline$Z$ & $R$ & $(3,3)$ & $(3,4)$ & $(3,5)$ & $(4,4)$ & $(4,5)$ & $(5,5)$ \\
\hline 10 & 3.005 & 0.0408 & 0.0377 & 0.0354 & 0.0428 & 0.0424 & 0.0440 \\
\hline 15 & 3.189 & 0.0412 & 0.0381 & 0.0358 & 0.0433 & 0.0429 & 0.0445 \\
\hline 20 & 3.476 & 0.0417 & 0.0386 & 0.0363 & 0.0440 & 0.0435 & 0.0452 \\
\hline 25 & 3.706 & 0.0424 & 0.0393 & 0.0370 & 0.0448 & 0.0443 & 0.0460 \\
\hline 30 & 3.929 & 0.0432 & 0.0401 & 0.0377 & 0.0457 & 0.0453 & 0.0470 \\
\hline 35 & 4.163 & 0.0441 & 0.0410 & 0.0386 & 0.0467 & 0.0463 & 0.0481 \\
\hline 40 & 4.270 & 0.0452 & 0.0420 & 0.0396 & 0.0479 & 0.0475 & 0.0494 \\
\hline 45 & 4.494 & 0.0463 & 0.0431 & 0.0407 & 0.0493 & 0.0489 & 0.0508 \\
\hline 50 & 4.654 & 0.0475 & 0.0443 & 0.0419 & 0.0507 & 0.0504 & 0.0524 \\
\hline 55 & 4.804 & 0.0489 & 0.0457 & 0.0432 & 0.0523 & 0.0520 & 0.0542 \\
\hline 60 & 4.912 & 0.0503 & 0.0472 & 0.0446 & 0.0541 & 0.0538 & 0.0560 \\
\hline 65 & 5.060 & 0.0519 & 0.0487 & 0.0462 & 0.0560 & 0.0557 & 0.0581 \\
\hline 70 & 5.311 & 0.0536 & 0.0504 & 0.0478 & 0.0580 & 0.0578 & 0.0602 \\
\hline 75 & 5.339 & 0.0553 & 0.0522 & 0.0496 & 0.0601 & 0.0600 & 0.0626 \\
\hline 80 & 5.463 & 0.0572 & 0.0541 & 0.0514 & 0.0624 & 0.0623 & 0.0650 \\
\hline 85 & 5.539 & 0.0591 & 0.0561 & 0.0534 & 0.0648 & 0.0647 & 0.0676 \\
\hline 90 & 5.710 & 0.0612 & 0.0582 & 0.0554 & 0.0673 & 0.0673 & 0.0704 \\
\hline 95 & 5.905 & 0.0633 & 0.0603 & 0.0575 & 0.0700 & 0.0700 & 0.0732 \\
\hline 100 & 5.857 & 0.0654 & 0.0626 & 0.0597 & 0.0727 & 0.0728 & 0.0762 \\
\hline 105 & 5.919 & 0.0677 & 0.0648 & 0.0619 & 0.0755 & 0.0757 & 0.0792 \\
\hline 110 & 5.993 & 0.0699 & 0.0672 & 0.0642 & 0.0783 & 0.0786 & 0.0824 \\
\hline 115 & 6.088 & 0.0722 & 0.0695 & 0.0665 & 0.0812 & 0.0816 & $0.0855(1)$ \\
\hline 120 & 6.175 & 0.0745 & 0.0719 & 0.0688 & 0.0841 & 0.0846 & $0.0887(1)$ \\
\hline
\end{tabular}


TABLE VI: The self energy function $F(\alpha Z)$, defined by $\Delta E^{\mathrm{SE}}=$ $\frac{\alpha}{\pi} \frac{(\alpha Z)^{4}}{n^{3}} F(\alpha Z) m c^{2}$, for H-like ions. $\left\langle v\left|h^{\mathrm{SE}}\right| v\right\rangle$ denotes the results of the model SE operator approach, $\left\langle v\left|V_{\mathrm{loc}}^{\mathrm{SE}}\right| v\right\rangle$ is the contribution of the local part of the model SE operator, and "Exact" labels the results of the exact calculation.

\begin{tabular}{|c|c|c|c|c|}
\hline$Z$ & State & $\left\langle v\left|V_{\text {loc }}^{\mathrm{SE}}\right| v\right\rangle$ & $\left\langle v\left|h^{\mathrm{SE}}\right| v\right\rangle$ & Exact \\
\hline \multirow[t]{6}{*}{10} & $4 s$ & 4.60 & 4.96 & 4.97 \\
\hline & $5 s$ & 4.59 & 4.96 & 4.99 \\
\hline & $5 p_{1 / 2}$ & -0.15 & -0.10 & -0.09 \\
\hline & $5 p_{3 / 2}$ & 0.17 & 0.15 & 0.15 \\
\hline & $5 d_{3 / 2}$ & -0.07 & -0.05 & -0.04 \\
\hline & $5 d_{5 / 2}$ & 0.07 & 0.05 & 0.04 \\
\hline \multirow[t]{6}{*}{20} & $4 s$ & 3.11 & 3.57 & 3.58 \\
\hline & $5 s$ & 3.11 & 3.57 & 3.59 \\
\hline & $5 p_{1 / 2}$ & -0.12 & -0.08 & -0.07 \\
\hline & $5 p_{3 / 2}$ & 0.18 & 0.16 & 0.17 \\
\hline & $5 d_{3 / 2}$ & -0.07 & -0.05 & -0.04 \\
\hline & $5 d_{5 / 2}$ & 0.07 & 0.05 & 0.05 \\
\hline \multirow[t]{6}{*}{40} & $4 s$ & 1.91 & 2.51 & 2.52 \\
\hline & $5 s$ & 1.90 & .50 & 2.52 \\
\hline & $5 p_{1 / 2}$ & -0.04 & 0.00 & 0.01 \\
\hline & $5 p_{3 / 2}$ & 0.22 & 0.21 & 0.21 \\
\hline & $5 d_{3 / 2}$ & -0.06 & -0.04 & -0.04 \\
\hline & $5 d_{5 / 2}$ & 0.07 & 0.06 & 0.05 \\
\hline \multirow[t]{6}{*}{60} & $4 s$ & 1.46 & 2.13 & 2.14 \\
\hline & $5 s$ & 1.44 & 2.12 & 2.14 \\
\hline & $5 p_{1 / 2}$ & 0.06 & .11 & 0.12 \\
\hline & $5 p_{3 / 2}$ & 0.26 & 0.26 & 0.26 \\
\hline & $5 d_{3 / 2}$ & -0.05 & -0.04 & -0.03 \\
\hline & $5 d_{5 / 2}$ & 0.08 & 0.06 & 0.06 \\
\hline \multirow[t]{6}{*}{83} & $4 s$ & 1.37 & 2.08 & 2.09 \\
\hline & $5 s$ & & 2.05 & 2.06 \\
\hline & $5 p_{1 / 2}$ & 0.21 & 0.29 & 0.30 \\
\hline & $5 p_{3 / 2}$ & 0.30 & 0.33 & 0.33 \\
\hline & $5 d_{3 / 2}$ & -0.04 & -0.03 & -0.02 \\
\hline & $5 d_{5 / 2}$ & 0.09 & 0.07 & 0.07 \\
\hline \multirow[t]{6}{*}{92} & $4 s$ & & 2.15 & 2.16 \\
\hline & $5 s$ & 1.40 & 2.10 & 2.12 \\
\hline & $5 p_{1 / 2}$ & 0.29 & 0.40 & 0.41 \\
\hline & $5 p_{3 / 2}$ & 0.32 & 0.36 & 0.36 \\
\hline & $5 d_{3 / 2}$ & -0.03 & -0.02 & -0.01 \\
\hline & $5 d_{5 / 2}$ & 0.09 & 0.08 & 0.07 \\
\hline
\end{tabular}

[52] V. A. Yerokhin, Phys. Rev. A 83, 012507 (2011).

[53] P.J. Mohr, Atomic Data and Nuclear Data Tables 29, 453 (1983).

[54] L. Labzowsky, I. Goidenko, M. Tokman and P. Pyykko, Phys.Rev.A, 59, 2707 (1999).

[55] P. Indelicato, J.P. Santos, S. Boucard, and J.-P. Desclaux, Eur. Phys. J. D 45, 155 (2007).

[56] I.A. Goidenko, Eur. Phys. J. D 55, 35 (2009).

[57] E. Eliav, U. Kaldor, P. Schwerdtfeger, B.A. Hess and Y. Ishikawa, Phys. Rev. Lett. 73, 3203 (1994).

[58] E. Eliav, U. Kaldor, and Y. Ishikawa, Phys. Rev. A 52, 2765 (1995). 
TABLE VII: The self energy function $F(\alpha Z)$, defined by $\Delta E^{\mathrm{SE}}=$ $\frac{\alpha}{\pi} \frac{(\alpha Z)^{4}}{n^{3}} F(\alpha Z) m c^{2}$, for neutral alkali metals in different potentials. $\left\langle v\left|h^{\mathrm{SE}}\right| v\right\rangle$ denotes the results of the model operator approach, calculated by averaging the model SE operator with the valence electron wave function in the corresponding potential. $\left\langle v\left|V_{\mathrm{loc}}^{\mathrm{SE}}\right| v\right\rangle$ is the contribution of the local part of the model SE operator, and "Exact" labels the results of the exact calculation of Ref. [20].

\begin{tabular}{|c|c|c|c|c|c|}
\hline Atom & Method & $x_{\alpha}=0$ & $x_{\alpha}=1 / 3$ & $x_{\alpha}=2 / 3$ & $x_{\alpha}=1$ \\
\hline \multirow[t]{3}{*}{$\mathrm{Na} 3 s_{1 / 2}$} & $\left\langle v\left|V_{\mathrm{loc}}^{\mathrm{SE}}\right| v\right\rangle$ & 0.166 & 0.163 & 0.176 & 0.214 \\
\hline & $\left\langle v\left|h^{\mathrm{SE}}\right| v\right\rangle$ & 0.170 & 0.168 & 0.183 & 0.224 \\
\hline & Exact [20] & 0.169 & 0.167 & 0.181 & 0.223 \\
\hline \multirow{3}{*}{$\mathrm{K} 4 s_{1 / 2}$} & $\left\langle v\left|V_{\mathrm{loc}}^{\mathrm{SE}}\right| v\right\rangle$ & 0.067 & 0.067 & 0.076 & 0.100 \\
\hline & $\left\langle v\left|h^{\mathrm{SE}}\right| v\right\rangle$ & 0.072 & 0.072 & 0.083 & 0.110 \\
\hline & Exact [20] & 0.072 & 0.072 & 0.083 & 0.110 \\
\hline \multirow[t]{3}{*}{$\mathrm{Rb} 5 s_{1 / 2}$} & $\left\langle v\left|V_{\mathrm{loc}}^{\mathrm{SE}}\right| v\right\rangle$ & 0.0187 & 0.0193 & 0.0230 & 0.0320 \\
\hline & $\left\langle v\left|h^{\mathrm{SE}}\right| v\right\rangle$ & 0.0229 & 0.0237 & 0.0284 & 0.0397 \\
\hline & Exact [20] & 0.0228 & 0.0236 & 0.0283 & 0.0396 \\
\hline \multirow[t]{3}{*}{ Cs $6 s_{1 / 2}$} & $\left\langle v\left|V_{\mathrm{loc}}^{\mathrm{SE}}\right| v\right\rangle$ & 0.0093 & 0.0097 & 0.0118 & 0.0171 \\
\hline & $\left\langle v\left|h^{\mathrm{SE}}\right| v\right\rangle$ & 0.0127 & 0.0132 & 0.0163 & 0.0236 \\
\hline & Exact [20] & 0.0126 & 0.0132 & 0.0162 & 0.0235 \\
\hline \multirow[t]{3}{*}{ Fr $7 s_{1 / 2}$} & $\left\langle v\left|V_{\mathrm{loc}}^{\mathrm{SE}}\right| v\right\rangle$ & 0.0047 & 0.0052 & 0.0067 & 0.0102 \\
\hline & $\left\langle v\left|h^{\mathrm{SE}}\right| v\right\rangle$ & 0.0069 & 0.0076 & 0.0099 & 0.0151 \\
\hline & Exact [20] & 0.0068 & 0.0075 & 0.0098 & 0.0150 \\
\hline
\end{tabular}


TABLE VIII: The self energy contribution to the $4 s-4 p_{1 / 2}, 4 s-$ $4 p_{3 / 2}, 4 p_{1 / 2}-4 d_{3 / 2}, 4 p_{3 / 2}-4 d_{3 / 2}$, and $4 p_{3 / 2}-4 d_{5 / 2}$ transition energies in $\mathrm{Cu}$-like ions, in eV. $\left\langle v\left|h^{\mathrm{SE}}\right| v\right\rangle$ denotes the results of the model operator approach, calculated by averaging the model SE operator with the Dirac-Kohn-Sham wave function of the valence electron. "Exact" labels the results of the exact calculation of Ref. [24].

\begin{tabular}{|c|c|c|c|}
\hline Ion & Transition & $\left\langle v\left|h^{\mathrm{SE}}\right| v\right\rangle$ & Exact [24] \\
\hline $\mathrm{Yb}^{41+}$ & $\begin{array}{c}4 s-4 p_{1 / 2} \\
4 s-4 p_{3 / 2} \\
4 p_{1 / 2}-4 d_{3 / 2} \\
4 p_{3 / 2}-4 d_{3 / 2} \\
4 p_{3 / 2}-4 d_{5 / 2}\end{array}$ & $\begin{array}{l}-1.29 \\
-1.21 \\
-0.10 \\
-0.18 \\
-0.14 \\
\end{array}$ & $\begin{array}{l}-1.28 \\
-1.21 \\
-0.11 \\
-0.18 \\
-0.14 \\
\end{array}$ \\
\hline $\mathrm{W}^{45+}$ & $\begin{array}{c}4 s-4 p_{1 / 2} \\
4 s-4 p_{3 / 2} \\
4 p_{1 / 2}-4 d_{3 / 2} \\
4 p_{3 / 2}-4 d_{3 / 2} \\
4 p_{3 / 2}-4 d_{5 / 2}\end{array}$ & $\begin{array}{l}-1.64 \\
-1.55 \\
-0.16 \\
-0.25 \\
-0.19 \\
\end{array}$ & $\begin{array}{l}-1.64 \\
-1.56 \\
-0.17 \\
-0.25 \\
-0.19 \\
\end{array}$ \\
\hline $\mathrm{Os}^{47+}$ & $\begin{array}{c}4 s-4 p_{1 / 2} \\
4 s-4 p_{3 / 2} \\
4 p_{1 / 2}-4 d_{3 / 2} \\
4 p_{3 / 2}-4 d_{3 / 2} \\
4 p_{3 / 2}-4 d_{5 / 2}\end{array}$ & $\begin{array}{l}-1.85 \\
-1.75 \\
-0.19 \\
-0.28 \\
-0.22 \\
\end{array}$ & $\begin{array}{l}-1.84 \\
-1.76 \\
-0.20 \\
-0.28 \\
-0.22 \\
\end{array}$ \\
\hline $\mathrm{Au}^{50+}$ & $\begin{array}{c}4 s-4 p_{1 / 2} \\
4 s-4 p_{3 / 2} \\
4 p_{1 / 2}-4 d_{3 / 2} \\
4 p_{3 / 2}-4 d_{3 / 2} \\
4 p_{3 / 2}-4 d_{5 / 2}\end{array}$ & $\begin{array}{l}-2.18 \\
-2.10 \\
-0.26 \\
-0.35 \\
-0.27 \\
\end{array}$ & $\begin{array}{l}-2.18 \\
-2.10 \\
-0.28 \\
-0.35 \\
-0.28 \\
\end{array}$ \\
\hline $\mathrm{Pb}^{53+}$ & $\begin{array}{c}4 s-4 p_{1 / 2} \\
4 s-4 p_{3 / 2} \\
4 p_{1 / 2}-4 d_{3 / 2} \\
4 p_{3 / 2}-4 d_{3 / 2} \\
4 p_{3 / 2}-4 d_{5 / 2}\end{array}$ & $\begin{array}{l}-2.57 \\
-2.49 \\
-0.35 \\
-0.43 \\
-0.34 \\
\end{array}$ & $\begin{array}{l}-2.56 \\
-2.50 \\
-0.37 \\
-0.43 \\
-0.34 \\
\end{array}$ \\
\hline $\mathrm{Bi}^{54+}$ & $\begin{array}{c}4 s-4 p_{1 / 2} \\
4 s-4 p_{3 / 2} \\
4 p_{1 / 2}-4 d_{3 / 2} \\
4 p_{3 / 2}-4 d_{3 / 2} \\
4 p_{3 / 2}-4 d_{5 / 2}\end{array}$ & $\begin{array}{l}-2.71 \\
-2.64 \\
-0.39 \\
-0.46 \\
-0.36 \\
\end{array}$ & $\begin{array}{l}-2.70 \\
-2.64 \\
-0.40 \\
-0.46 \\
-0.37 \\
\end{array}$ \\
\hline $\mathrm{Th}^{61+}$ & $\begin{array}{c}4 s-4 p_{1 / 2} \\
4 s-4 p_{3 / 2} \\
4 p_{1 / 2}-4 d_{3 / 2} \\
4 p_{3 / 2}-4 d_{3 / 2} \\
4 p_{3 / 2}-4 d_{5 / 2} \\
\end{array}$ & $\begin{array}{l}-3.85 \\
-3.88 \\
-0.73 \\
-0.70 \\
-0.56 \\
\end{array}$ & $\begin{array}{l}-3.85 \\
-3.89 \\
-0.74 \\
-0.71 \\
-0.57 \\
\end{array}$ \\
\hline $\mathrm{U}^{63+}$ & $\begin{array}{c}4 s-4 p_{1 / 2} \\
4 s-4 p_{3 / 2} \\
4 p_{1 / 2}-4 d_{3 / 2} \\
4 p_{3 / 2}-4 d_{3 / 2} \\
4 p_{3 / 2}-4 d_{5 / 2}\end{array}$ & $\begin{array}{l}-4.24 \\
-4.32 \\
-0.87 \\
-0.79 \\
-0.63\end{array}$ & $\begin{array}{l}-4.24 \\
-4.33 \\
-0.88 \\
-0.79 \\
-0.65\end{array}$ \\
\hline
\end{tabular}


TABLE IX: The self energy contribution to the binding energy of the valence electrons in Rg, Cn, E119 and E120, in eV. In this work, the perturbation theory (PT) value is obtained by averaging the model SE operator with the Dirac-Fock wave function of the valence electron, while the DF and total DF values are obtained by including this operator into the DF equations. The DF value is given by the SE contribution to the one-electron binding energy whereas the total DF value is obtained as the difference between the SE contributions to the total DF energies of the atom and the ion (the ${ }^{2} S_{1 / 2} \rightarrow{ }^{1} S_{0}$ and the ${ }^{1} S_{0} \rightarrow{ }^{2} S_{1 / 2}$ transitions are considered for $\mathrm{Rg}$ and $\mathrm{Cn}$, respectively; see the text of the paper). In Refs. [54, 56], the calculations were performed with a local DF potential.

\begin{tabular}{|c|c|c|c|c|c|}
\hline Atom & Valence electron & Method & This work & Ref. [56] & Other works \\
\hline \multirow[t]{5}{*}{$\mathrm{Rg}$} & $7 s$ & PT & -0.088 & -0.089 & $-0.087^{a}$ \\
\hline & & DF & -0.105 & -0.102 & \\
\hline & & Total DF & -0.096 & & \\
\hline & & Welton method & & & $-0.084^{b}$ \\
\hline & & Local SE pot. & & & $-0.089^{c}$ \\
\hline \multirow[t]{4}{*}{$\mathrm{Cn}$} & $7 \mathrm{~s}$ & PT & -0.101 & -0.103 & \\
\hline & & DF & -0.105 & -0.110 & \\
\hline & & Total DF & -0.098 & & \\
\hline & & Local SE pot. & & & $-0.091^{c}$ \\
\hline \multirow[t]{4}{*}{$\overline{\text { E119 }}$} & $8 s$ & PT & -0.0233 & & $-0.0274^{a}$ \\
\hline & & DF & -0.0250 & & \\
\hline & & Total DF & -0.0232 & & \\
\hline & & Local SE pot. & & & $-0.0210^{c}$ \\
\hline \multirow[t]{4}{*}{ E120 } & $8 s$ & PT & -0.0331 & & \\
\hline & & DF & -0.0265 & & \\
\hline & & Total DF & -0.0250 & & \\
\hline & & Local SE pot. & & & $-0.0226^{c}$ \\
\hline
\end{tabular}

${ }^{a}$ Taken from Ref. [54]; ${ }^{b}$ Taken from Ref. [55]; ${ }^{c}$ Taken from Ref. [31].

TABLE X: The screened self energy for the $2 s, 2 p_{1 / 2}$, and $2 p_{3 / 2}$ states of Li-like ions, in eV. The Kohn-Sham (KS) and Dirac-Fock (DF) results are obtained by calculating the total ion energy with the model SE operator included into the KS and DF equations, respectively, and substructing the related energies evaluated without the model SE operator and the self energy contributions calculated with the hydrogenlike wave functions. Comparison with the calculations performed by perturbation theory (PT) in the Kohn-Sham potential [26, 27] is given.

\begin{tabular}{cccccc}
\hline \hline$Z$ & State & KS & DF & PT [26] PT [27] \\
\hline 20 & $2 s$ & -0.047 & -0.045 & -0.044 & -0.046 \\
& $2 p_{1 / 2}$ & -0.009 & -0.008 & -0.008 & -0.008 \\
& $2 p_{3 / 2}$ & -0.012 & -0.011 & -0.013 & -0.013 \\
\hline 40 & $2 s$ & -0.277 & -0.269 & & -0.260 \\
& $2 p_{1 / 2}$ & -0.063 & -0.059 & & -0.059 \\
& $2 p_{3 / 2}$ & -0.077 & -0.073 & & -0.085 \\
\hline 50 & $2 s$ & -0.50 & -0.49 & -0.48 & \\
& $2 p_{1 / 2}$ & -0.13 & -0.12 & -0.12 & \\
& $2 p_{3 / 2}$ & -0.14 & -0.14 & -0.16 & \\
\hline 60 & $2 s$ & -0.84 & -0.82 & & -0.80 \\
& $2 p_{1 / 2}$ & -0.24 & -0.24 & & -0.25 \\
& $2 p_{3 / 2}$ & -0.24 & -0.23 & & -0.27 \\
\hline 74 & $2 s$ & -1.58 & -1.55 & & -1.55 \\
& $2 p_{1 / 2}$ & -0.57 & -0.56 & & -0.62 \\
& $2 p_{3 / 2}$ & -0.45 & -0.43 & & -0.53 \\
\hline 83 & $2 s$ & -2.35 & -2.25 & -2.32 & -2.26 \\
& $2 p_{1 / 2}$ & -0.97 & -0.98 & -1.07 & -1.07 \\
& $2 p_{3 / 2}$ & -0.65 & -0.61 & -0.75 & -0.76 \\
\hline 92 & $2 s$ & -3.47 & -3.19 & & -3.81 \\
& $2 p_{1 / 2}$ & -1.67 & -1.69 & & -1.58 \\
& $2 p_{3 / 2}$ & -0.91 & -0.86 & & -1.04 \\
\hline \hline
\end{tabular}

